Document downloaded from:

http://hdl.handle.net/10251/63890

This paper must be cited as:

Cambra López, M.; Torres Salvador, AG.; Aarnink, AJA.; Ogink, NWM. (2011). Source analysis of fine and coarse particulate matter from livestock houses. Atmospheric Environment. 45(3):694-707. doi:10.1016/j.atmosenv.2010.10.018.

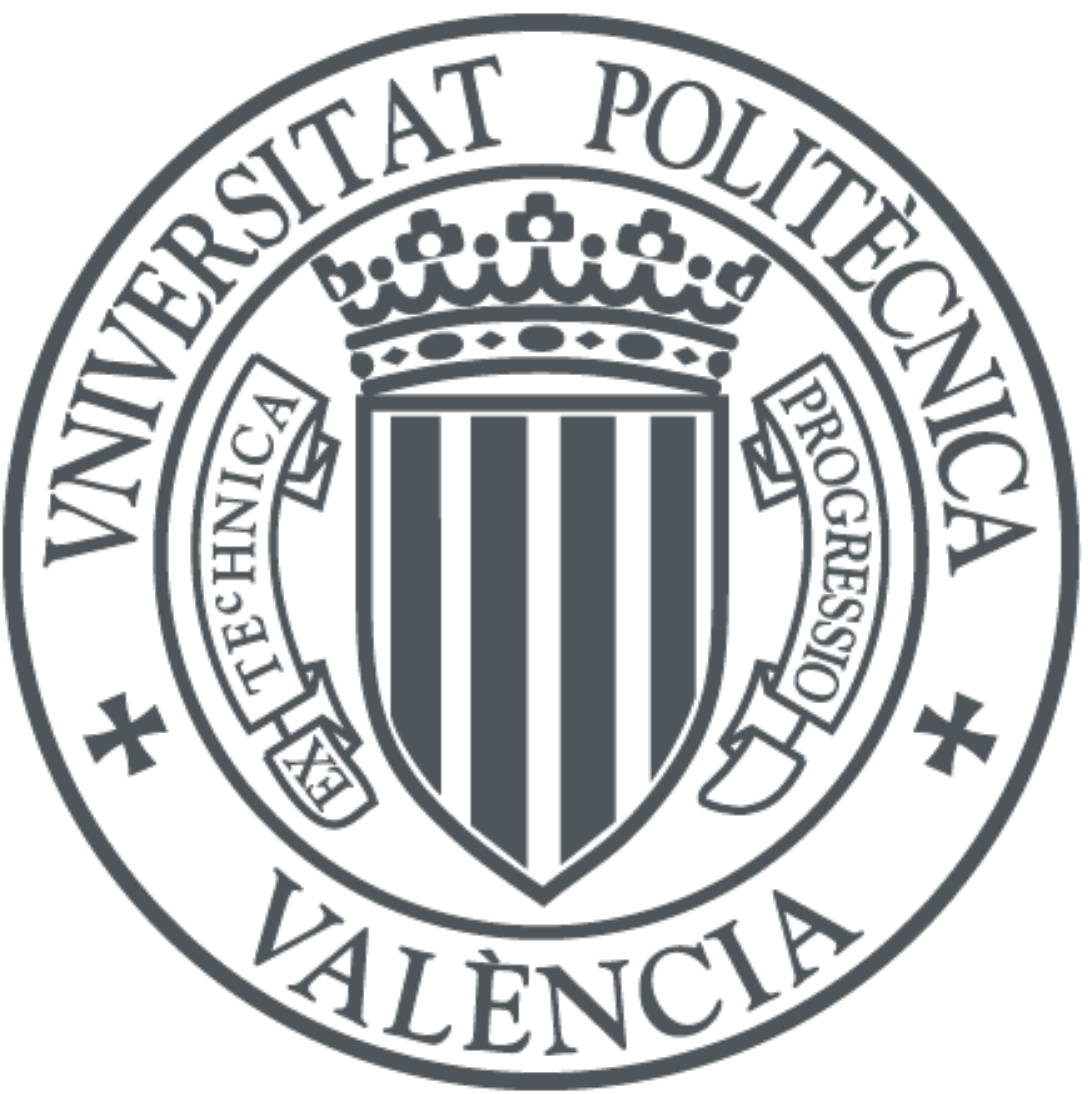

The final publication is available at

http://dx.doi.org/10.1016/j.atmosenv.2010.10.018

Copyright Elsevier

Additional Information 


\section{Source analysis of fine and coarse particulate matter from}

\section{2 livestock houses}

3 M. Cambra-López ${ }^{1}$, A. G. Torres ${ }^{1}$, A. J. A. Aarnink ${ }^{2}$, N. W. M. Ogink ${ }^{2}$

$4 \quad{ }^{1}$ Institute of Animal Science and Technology, Universidad Politécnica de Valencia. Camino de 5 Vera s.n. Valencia, Spain.

$6 \quad{ }^{2}$ Wageningen UR Livestock Research. P.O. Box 65, 8200 AB Lelystad, The Netherlands.

8 Abstract. The analyses of the different sources which can contribute to particulate matter (PM)

9 emissions from livestock houses are essential to develop adequate reduction techniques. The

10 aim of this study was to morphologically and chemically characterize several sources of PM

11 from livestock houses. We collected known sources of PM from different housing systems for

12 poultry and pigs, which were later aerosolized in a customized laboratory dust generator to

13 collect fine and coarse PM samples. These samples were morphologically and chemically

14 characterized using scanning electron microscopy with X-ray microanalysis to develop

15 comprehensive morphological and chemical source profiles. Moreover, source particle-size

16 distribution was determined. Results showed distinct and unique particle morphologies in

17 collected sources from different housing systems for poultry and pigs. Although presence of N,

$18 \mathrm{Na}, \mathrm{Mg}, \mathrm{Al}, \mathrm{Si}, \mathrm{P}, \mathrm{S}, \mathrm{Cl}, \mathrm{K}$, and $\mathrm{Ca}$ were identified in all sources, their relative element

19 concentrations varied amongst sources and could be used to discriminate amongst them. Particle

20 size and size distribution also varied amongst sources (size ranged from $2.1 \mu \mathrm{m}$ to $18.1 \mu \mathrm{m}$

21 projected area diameter), and mainly depended on its mineral or organic origin. The results from

22 this work can be useful information for source identification and quantification in PM from

23 livestock houses, improving the understanding of how PM is generated in such environments,

24 and developing strategies for its reduction.

25 Keywords: Characterization, Dust sources, Livestock Housing, Source profile, SEM-EDX. 


\section{Introduction}

High concentrations of particulate matter (PM) can threaten the environment as well as the health and welfare of humans and animals. A close relation between PM air pollution, respiratory and cardiovascular disease, and mortality has been reported (Pope et al., 2002).

31 Particulate matter air pollution can also cause reduced visibility, vegetation stress, and ecosystems alteration (Grantz et al., 2003). Furthermore, small PM can have a direct radiative effect because they scatter and absorb solar and infrared radiation in the atmosphere (IPCC, 2001).

Livestock houses are important contributors to ambient fine (PM2.5) and coarse (PM10-

2.5) PM emissions (Takai et al., 1998). In livestock houses, PM has a high organic content, because it is mainly composed of primary coarse particles which originate from feed, manure, bedding, and animal's skin, feathers, and hair (Donham et al., 1986; Heber et al., 1988). Inside livestock houses, numerous studies have reported higher prevalence of respiratory diseases in livestock farmers compared with other occupations (Bongers et al., 1987; Donham et al., 1984).

41 Furthermore, animal's respiratory health may also be compromised by PM (Donham and Leininger, 1984).

The best approach to reduce PM in and from livestock houses seems to be to prevent it

44 from being generated. Improved knowledge on where PM comes from in livestock houses and the identification of the major sources of PM, can help develop efficient and practical sourcespecific reduction techniques to comply with European threshold limits set in air quality regulations, and to protect the environment, and human and animal health and welfare.

Moreover, the characterization of particle properties offers the potential to specifically identify and quantify sources of PM (Casuccio et al., 2004); but to date, there is lack of detailed

50 characterization of particle size, morphology, and chemical composition from sources in

51 livestock houses. With comprehensive particle characterization and detailed source profiles,

52 better estimates of contributions to more specific sources would be possible (Watson et al., 
2002). Therefore, the development of specific, accurate, and detailed source profiles for known

sources from livestock houses is encouraged.

The aim of this study was to morphologically and chemically characterize individual fine and coarse PM from known sources collected from different housing systems for poultry and pigs, and to develop comprehensive morphological and chemical source profiles. More specifically, the objectives of this study were (i) to identify unique source-specific particle morphologies and define homogeneous morphological types of particles; (ii) to identify element source compositions and compare them amongst sources; and (iii) to determine particle size, and size distribution in each source. The results from this work can be useful information for source identification and quantification in livestock houses, improving the understanding of how PM is generated in such environments, and developing strategies for its reduction.

\section{Material and methods}

\subsection{Livestock houses and source types}

A total of 48 samples from known sources of PM were collected at 14 different livestock locations in The Netherlands, including seven different housing systems for poultry and pigs. Two farms were sampled for each livestock housing system. Table 1 describes the surveyed livestock houses for the different livestock species, and the collected PM sources at each farm. All farms were sampled for manure and concentrate feed. The rest of collected PM source types depended on the housing system.

\subsection{Known source sample collection and preparation}

Sampling was conducted during morning (from 09:00 to 12:00) at each livestock farm. A representative sample from each PM source was obtained by randomly sampling different locations in the livestock house. A total of 200 to 500 grams of feed, clean bedding, and fresh manure samples were collected at each location from the flooring surfaces. A total of 10 to 50 grams of hair, feathers, and skin, were directly collected from clean animals. Samples were stored in clean sealable polyethylene bags, and transported to the laboratory and stored under 
refrigeration. Each sample was then mixed to achieve a uniform sample and the samples were dried in the oven for $12 \mathrm{~h}$ at $70^{\circ} \mathrm{C}$. Dried samples were crushed in a ball mill during $1.5 \mathrm{~min}$ at $250 \mathrm{rpm}$. Dried and milled samples were stored at room temperature.

A representative sample of ambient outdoor fine and coarse PM was also collected upwind, at each location on each sampling day. These PM samples were collected using a virtual cascade impactor (RespiCon, Wetzlar, Germany). This impactor simultaneously sampled PM2.5 and PM10-2.5 particles. A portable pump (Genie VSS5, Buck Inc, U.S.) was used to draw air through the impactor at constant flow of $3.11 \mathrm{~L} \mathrm{~min}^{-1}$. Particles were collected on polycarbonate filters ( $37 \mathrm{~mm} \varnothing, 5 \mu \mathrm{m}$ pore size), and stored before analysis. Sampling time varied from $30 \mathrm{~min}$ to $60 \mathrm{~min}$, aiming at particle loads appropriate for single-particle analysis of 5 to $20 \mu \mathrm{g}$ particles $\mathrm{cm}^{-2}$ filter (Willis et al., 2002).

\subsection{Size-segregated PM generation and measurements}

To obtain size-segregated PM samples from the different known sources, a mechanical agitation system was used. Each milled source was aerosolized by a customized laboratory stainless steel dust generator (Figure 1). The amount of sample and the dust generation time were adjusted to obtain particle loads of 5 to $20 \mu \mathrm{g}$ particles $\mathrm{cm}^{-2}$ filter (Willis et al., 2002). Approximately 0.2 grams of milled feathers and skin, 2 to 3 grams of milled manure, hair and wood shavings, and 40 grams of milled feed were used in the dust generator, rotated at $200 \mathrm{rpm}$. Sampling time varied from $1 \mathrm{~min}$ (feathers), $2 \mathrm{~min}$ (manure), $4 \mathrm{~min}$ (skin), $20 \mathrm{~min}$ (hair), $3 \mathrm{~h}$ (wood shavings), and $7 \mathrm{~h}$ (feed). The PM2.5 and PM10-2.5 generated particles during agitation were collected using a virtual cascade impactor (RespiCon, Wetzlar, Germany) and a portable

100 pump, using polycarbonate filters. Loaded filter samples were stored in sealed filter cassettes at room temperature $\left(20-25^{\circ} \mathrm{C}\right)$ before analysis.

103 Technik GmbH \& Co., Ainring, Germany) was used during the dust generation process to

104 monitor particle-size distribution (PSD) per source. The inlet of the device was connected to the

105 dust generation chamber. Air was sampled through the inlet at $1.2 \mathrm{~L} \mathrm{~min}^{-1}$. The optical particle 
counter sampled and counted particles in 31 size ranges, from $0.25 \mu \mathrm{m}$ to $32 \mu \mathrm{m}$ in diameter

107 using light scattering principle. Recorded values were stored every 6 s. Sampling time was 7

108 min per sample. This instrument was also used to determine PSD of outdoor particles, outside

109 farm locations.

\section{2.4. Scanning electron microscopy analysis}

111 All samples collected on polycarbonate filters were analyzed using high-resolution

112 scanning electron microscopy (SEM) (JEOL, JSM-5410) combined with energy-dispersive X-

113 ray analysis (EDX) (Link Tetra Oxford Analyzer). A small section (approximately $1 \mathrm{~cm}^{2}$ ) of the

114 as-collected polycarbonate filter from fine and coarse fractions was cut and mounted on a 12-

$115 \mathrm{~mm}$ carbon stub, and coated with carbon to make it conductive to the SEM electron beam.

116 The SEM-EDX was conducted manually, operated under the same conditions

117 throughout the study in the secondary electron mode: accelerating voltage $10 \mathrm{keV}$, working

118 distance $15 \mathrm{~mm}$, electron probe current of $3 \mathrm{nA}$, magnifications 1000x for coarse PM, and

119 1800x for fine PM, and X-ray acquisition time 60 s per particle.

Uniformity of particle deposition on the filter was verified examining the filter prior to analysis at low magnification (300x). Then, at least three fields of view per filter sample were analyzed. On each analyzed field, both an image (photomicrograph at 1000x or 1800x) and single particle X-ray spectra of every particle found in that field were obtained and stored.

124 Within each field, the minimum projected area diameter for the coarse particles was set at $1 \mu \mathrm{m}$.

125 The minimum projected area diameter for the fine particles was set at $0.1 \mu \mathrm{m}$ (Conner et al.,

126 2001). These limits were set because otherwise the detection and analysis of smaller particles

127 was not reliable at the used magnifications. A total of 25 to 50 individual particles were

128 analyzed in each sample. All spectra were normalized to $100 \%$ and checked manually to correct

129 for the contribution of the filter material (composed of carbon and oxygen).

130 Photomicrographs (images) of each field of view were acquired at normal gray and 131 saved in tif format (1024x768 resolution). These images were further analyzed using the Object 
132 Based Image Analysis (OBIA) approach (Blaschke, 2010) using FETEX 2.0 software (Ruiz et

133 al., 2010). This image analysis and processing system automatically detected each particle

134 object and calculated the particle projected area. From the particle area, the projected area

135 diameter $\left(D_{p}\right)$ was calculated, defined as the diameter of a perfect circle fitted to the measured

136 area of the particle (equation 1).

$137 \quad D_{p}=2 \times \sqrt{\frac{\text { Area }}{\pi}}$

\section{2.5. Data analyses}

Particle types and morphologies were qualitatively analyzed based on the SEM images.

140 These particle types were morphologically described in terms of shape (rounded, spherical,

141 fibrous, flake, angular, aggregate, irregular, flattened, long-thin), surface (layered, smoothed,

142 cracked), edges and borders (sharpness), texture (smooth, grape-like, and rough), and opacity,

143 amongst others (McCrone, 1992; NIST, 2010). In this way, different types of particles were

144 determined in each source, in fine and coarse PM. More than 300 images were qualitatively

145 analyzed.

146 Particle chemical compositions were summarized to obtain the average relative element

147 concentrations per source in fine and coarse PM, pooled by livestock category. The relative

148 element composition of the PM in the different sources and in each fraction was compared using

149 analysis of variance with SAS software (SAS, 2001). To test multivariate differences between

150 sources, and identify which elements (variables) discriminated best amongst sources per

151 fraction, we performed a stepwise discriminant analysis using SAS software (SAS, 2001).

152 Hierarchical cluster analysis was used to provide evidence of similarities and differences within

153 and amongst sources from different livestock categories, using the average relative element

154 concentrations per source in fine and coarse PM, for each livestock category and housing

155 system. We used Ward's minimum-variance method for clustering and the squared Euclidean

156 distance as a measure of similarity between clusters using SAS software (SAS, 2001). 
158 PM, pooled by livestock category. The average $D_{p}$ of the PM in the different sources and in 159 each fraction was compared using analysis of variance with SAS software (SAS, 2001). from the frequency of particles $\left(\mathrm{F}_{\mathrm{i}}\right)$ within a size range $\left(\Delta \mathrm{d}_{\mathrm{i}}\right)$ in each source. The standardized number fraction of particles for the $\mathrm{i}^{\text {th }}$ size range was calculated with equation 2 :

$$
\Delta f_{i}=\frac{\left(\frac{F_{i}}{\Delta d_{i}}\right)}{N}
$$

164 where: $\Delta \mathrm{f}_{\mathrm{i}}=$ Standardized fraction in units of $\mu \mathrm{m}^{-1}$ for the $\mathrm{i}^{\text {th }}$ size range, $\mathrm{F}_{\mathrm{i}}=$ Frequency of particles within a size range, $\Delta \mathrm{d}_{\mathrm{i}}=$ Particle size range, calculated as the difference between the upper and lower limit of the sampling interval (size range measured by the instrument) within each group of particles, $\mathrm{N}=$ Total number of particles measured by the instrument (sum of all

168 size ranges). concentrations by an estimated particle mass per source, assuming all particles were spherical, and assuming a value for particle density. Density values of $1.2 \mathrm{~g} \mathrm{~cm}^{-3}$ (feathers), $2.6 \mathrm{~g} \mathrm{~cm}^{-3}$

172 (feed), $1.3 \mathrm{~g} \mathrm{~cm}^{-3}$ (hair), $1.5 \mathrm{~g} \mathrm{~cm}^{-3}$ (manure and wood shavings), $1.4 \mathrm{~g} \mathrm{~cm}^{-3}$ (skin), and $2.1 \mathrm{~g} \mathrm{~cm}^{-}$

$173{ }^{3}$ (outside) were used (McCrone, 1992). The calculation of particle mass from particle numbers

174 per source was done following equation 3:

$$
m_{i}=n_{i} \times \rho_{p} \times v_{p i}=n_{i} \times \rho_{p} \times\left[\frac{4}{3} \times \pi \times r_{i}^{3}\right]=n_{i} \times \frac{\rho_{p} \times \pi \times\left(d_{g_{i}}\right)^{3}}{6}
$$
where: $\mathrm{m}_{\mathrm{i}}=$ particle mass for the $\mathrm{i}^{\text {th }}$ size range of particles, $\mathrm{n}_{\mathrm{i}}=$ number of particles measured by

177 the instrument for the $\mathrm{i}^{\text {th }}$ size range, $\rho_{\mathrm{p}}=$ particle density per source, $\mathrm{v}_{\mathrm{pi}}=$ particle spherical

178 volume for the $\mathrm{i}^{\text {th }}$ size range, $\mathrm{r}_{\mathrm{i}}=$ equivalent radius of a spherical particle for the $\mathrm{i}^{\text {th }}$ size range,

$179 \mathrm{~d}_{\mathrm{gi}}=$ mean geometric particle diameter measured by the instrument in the $\mathrm{i}^{\text {th }}$ size range. 
180 This size distribution was also standardized and divided by the total mass of particles to obtain

181 the standardized mass fraction in the same way as for standardized number fraction (equation

182 2).

\section{3. Results}

184 3.1. Particle types and morphology (fine and coarse)

Different types of particles were identified per source and thoroughly described below.

\subsubsection{Feathers}

Feathers showed a mixture of irregular, mostly flattened particles in fine and coarse PM.

188 Three morphological types were identified: soft and "fluffy" particles, sometimes bent (Figure

$1892 \mathrm{a}$ and $\mathrm{b}$ ); rounded, flake-like flattened, sometimes aggregate particles with rough texture

190 (Figure 2c and d); and stiff, elongated, and pointed particles (Figure 2e and f). Each type

191 generally coincided with different livestock categories. In broilers, small soft and "fluffy"

192 particles were dominant in fine and coarse PM. In laying hens, besides showing some soft and

193 "fluffy" structures, also flake-like flattened particles and elongated particles were dominant in

194 fine and coarse PM. Turkeys showed mostly soft and "fluffy" particles in the fine fraction

195 (Figure 2g); whereas flake-like flattened and elongated particles were abundant in coarse PM

196 (Figure 2h).

$197 \quad$ 3.1.2. Feed

$198 \quad$ Four general morphological types of feed particles were identified: rounded and

199 deposited particles, sometimes fragmented (mainly seen in broilers and turkeys) (Figure 3a and

200 b); geometric quadrangular, cubic (Figure 3c and d) or bar-shaped particles (Figure 3e and f);

201 and angular, cracked, fragmented particles (Figure 3g and h). All types were randomly found in

202 fine and coarse PM amongst all livestock categories. 
Pig's hair showed long-thin particles. Two types of hair particles were identified in fine and coarse PM: thin pointed particles (Figure $4 \mathrm{a}$ and b); and striated tubular particles (Figure 4c and d).

\subsubsection{Manure}

Manure particles showed two morphological types: rounded, spherical, and smooth

209 particles; and fragmented, rough, and angular particles. Rounded spheres were only identified in

210 poultry excreta, in fine and coarse PM. Apart from rounded spheres, irregular and angular

211 particles were also identified in poultry excreta. Rounded spheres were sometimes present as

212 individual particles (Figure 5a), and agglomerated with fragmented angular particles (Figure

$2135 b$ ), or highly agglomerated forming grape-like structures (Figure $5 \mathrm{c}$ and d). Rough and ciliated

214 rounded spheres were identified in turkeys and laying hens manure (Figure 5e and f).

215 Fragmented, layered, angular particles were the dominant particles in pigs manure in fine

216 (Figure 6a and b) and coarse PM (Figure 6c and d).

\section{$217 \quad$ 3.1.5.Skin}

218 Sow's skin particles were morphologically homogeneous and showed a single type, as

219 big, rounded, thin, flattened, flake-like, transparent particles in fine (Figure 7a and c) and coarse

220 PM (Figure 7b and d). These flake-like particles presented a smooth surface (Figure 7a and c),

221 although some of them presented rough surfaces caused by deposited particles on top (Figure $7 \mathrm{~b}$ 222 and d).

\subsubsection{Wood shavings}

Wood shaving particles showed two types of particles: flattened, round with irregular

225 borders, others elongated and bent in fine PM (Figure 8a and c); and mostly fibrous particles

226 with sharp edges identified in coarse PM (Figure 8b and d). 


\subsubsection{Outside source}

Particles from outside farm sources showed heterogeneous morphologies. Dominant particles were generally small, irregular angular, cracked fragmented particles (sometimes aggregate) (Figure 9a and b); and geometric quadrangular, bar-shaped or cubic particles (Figure

$2319 \mathrm{c}$ and $\mathrm{d})$.

\subsection{Chemical composition (fine and coarse)}

Average relative element concentrations were calculated per source in fine and coarse

234 PM, pooled by livestock category. Figure 10 (fine PM) and Figure 11 (coarse PM) present

235 average particle element relative concentration per source, together with significant differences

236 in average values of element concentrations amongst sources. Hair was not included in the

237 analysis because it showed very high carbon and oxygen peak in the SEM-EDX which was

238 confused with the background filter composition. Presence of $\mathrm{N}, \mathrm{Na}, \mathrm{Mg}, \mathrm{Al}, \mathrm{Si}, \mathrm{P}, \mathrm{S}, \mathrm{Cl}, \mathrm{K}$,

239 and Ca were identified in all sources, in fine and coarse PM. Generally, differences in these

240 elements amongst sources were obtained between feed, outside, wood, skin, and the rest of

241 sources; or between manure and the rest of sources. Manure showed the highest relative levels

242 of N, Mg, P, and K; skin showed the highest S levels; wood shavings showed the highest levels

243 of $\mathrm{Cl}$ and $\mathrm{Na}$; feed showed the highest levels of $\mathrm{Si}$ and $\mathrm{Ca}$; and outside source showed the

244 highest levels of $\mathrm{Al}$ in fine PM. Traces of heavy elements (metals), with atomic numbers greater

245 than 20 (such as $\mathrm{Fe}, \mathrm{Ni}, \mathrm{Cu}, \mathrm{Zn}, \mathrm{Ag}, \mathrm{Pb}, \mathrm{Sn}, \mathrm{Ba}$, and $\mathrm{Cu}$ ) were mainly identified in feed and

246 outside, and to a smaller extent in wood shavings. Other elements not shown in Figure 10 and

247 Figure 11, were detected in some particles in fine and coarse PM (Co in feed, manure, and

248 outside), and others only in coarse PM ( $\mathrm{Br}, \mathrm{Ti}, \mathrm{V}$, and $\mathrm{Sb}$ in feed, wood shavings, and outside),

249 in relative concentrations below $0.2 \%$, and showing no statistical significant differences

250 amongst sources.

251 Results from the discriminant analysis confirmed the differences in relative element

252 concentrations amongst sources presented in Figure 10 and Figure 11. The first five common

253 variables that best discriminated amongst sources were $\mathrm{P}, \mathrm{N}, \mathrm{Cl}, \mathrm{S}$, and $\mathrm{K}$. Table 2 and Table 3 
254 show the summary of the stepwise discriminant analysis for each variable considered. In fine

$255 \mathrm{PM}$, order of entrance into the discriminant process was: $\mathrm{P}, \mathrm{N}, \mathrm{Cl}, \mathrm{S}, \mathrm{K}, \mathrm{Si}, \mathrm{Na}, \mathrm{Al}, \mathrm{Ca}, \mathrm{Mg}$, and

256 Sn (Table 2). In coarse PM, the order of entrance into the discriminant process was: P, N, K, S,

$257 \mathrm{Cl}, \mathrm{Al}, \mathrm{Ca}, \mathrm{Cr}, \mathrm{Na}, \mathrm{Mg}, \mathrm{Ba}$, and $\mathrm{Fe}$ (Table 3).

258 Cluster analysis revealed three major source groups in fine and coarse PM: one

259 including mainly feed and outside source, another including mainly manure source, and the

260 third one including feathers and skin; being wood shavings either grouped together with feathers

261 and skin or feed and outside. Figure 12 and Figure 13 present the groupings which result from

262 cluster analysis. The horizontal distance between each group is a representation of their

263 dissimilarity. When data were joined into three groups or clusters, the proportion of variance

264 accounted for by the clusters was $46 \%$ for fine and $54 \%$ for coarse PM; but when data were

265 joined into nine (fine PM) or eight (coarse PM) clusters, this variance reached $80 \%$. Cluster

266 groupings showed similarities and dissimilarities between sources amongst livestock categories,

267 especially within and amongst poultry categories (being for instance broiler's and turkey's

268 manure sources closely related between them, and more closely related to laying hens manure

269 than to pig's manure) and mostly between poultry and pigs (being associations generally made

270 accounting for animal species).

\section{$271 \quad 3.3$. Size and size distributions}

272

In each source, particle size, expressed as $\mathrm{D}_{\mathrm{p}}$, was determined from SEM images using

273 image analysis software. Particle-size distribution was determined by the light scattering

274 principle during aerosolization in the dust generator.

\subsubsection{Particle size}

276

For all sources (except for hair) average $\mathrm{D}_{\mathrm{p}}$ in fine $\mathrm{PM}$ was from $35 \%$ to $46 \%$ lower $(\mathrm{P}<$

0.005) compared with coarse PM. Skin and hair showed the largest particle sizes ( $D_{p}$ equal to 13

$278 \mu \mathrm{m}$ in fine PM, and $18 \mu \mathrm{m}$ in coarse PM); whereas feed and outside particles showed the lowest 
sizes $\left(D_{p}\right.$ equal to $2 \mu \mathrm{m}$ in fine $P M$, and $3 \mu \mathrm{m}$ in coarse $\left.P M\right)$. Average $D_{p}$ (standard deviation,

280 SD) for the different sources in fine and coarse PM are shown in Table 4.

\subsubsection{Particle-size distribution}

Figure 14 shows the average particle number-size distribution per source in log-scale,

283 calculated from the average number of particles per size range measured for each source. All

284 sources showed the highest number of particles in the lowest size ranges and the lowest number

285 of particles in the highest size ranges. Particles in the size range from $0.25 \mu \mathrm{m}$ to $0.28 \mu \mathrm{m}$ were

286 the most abundant in all sources, being this the minimum size range measured by the

287 instrument. From approximately $0.6 \mu \mathrm{m}$, differences amongst size distributions from sources

288 became evident. From this size range onwards, two different size distributions were observed:

289 size distribution from feed and outside which decreased more or less linearly; and size

290 distribution from the rest of sources which showed two peaks, one at $0.8 \mu \mathrm{m}$ to $0.9 \mu \mathrm{m}$, and

291 another at 4 to $5 \mu \mathrm{m}$. All sources showed a peak in the last size range (particles bigger than 32

$292 \mu \mathrm{m})$, indicating a relatively high number of very big particles.

Figure 15 shows the average particle mass-size distributions per source in log-scale,

294 calculated from the average mass of particles per size range for each source. Particle mass-size

295 distributions showed high masses in the lowest size ranges, in the middle size ranges, but also in

296 the highest size ranges. High mass for feed and outside was observed in the minimum size range

297 measured by the instrument (size range from $0.25 \mu \mathrm{m}$ to $0.28 \mu \mathrm{m}$ ). For the rest of sources, high

298 masses were found at 4 to $5 \mu \mathrm{m}$, where feed and outside showed their minimum mass. Above 5

$299 \mu \mathrm{m}$, the mass of feathers and hair decreased more sharply, showing lower masses compared

300 with manure, skin, and wood shavings. Above $5 \mu \mathrm{m}$, feed and outside masses increased.

301 Manure's mass distribution showed four very clear peaks at $0.25 \mu \mathrm{m}, 0.4 \mu \mathrm{m}, 0.8 \mu \mathrm{m}$, and 4

$302 \mu \mathrm{m}$. Again, all sources showed a peak in the last size range, corresponding to particles bigger

303 than $32 \mu \mathrm{m}$.

\section{4. Discussion}


306 livestock housing systems for poultry and pigs demonstrated that sources of PM differed in

307 particle morphology, element composition, and size. This study gives a detailed and complete

308 analysis of potential sources of PM from livestock houses including different housing systems

309 for poultry and pigs in size-segregated PM.

310 Qualitative results revealed different particle morphological types and unique

311 morphological features related to each source. Some of the identified particle types coincided

312 and could be related to a specific livestock category (e.g. type of feathers and manure), although

313 others were generally randomly found in all livestock categories (e.g. types of feed particles).

314 The main differences amongst sources were found between hair and skin and the rest of sources,

315 because these presented the most well defined and homogeneous particle types and

316 morphologies. Furthermore, the use of digital image analysis software could be useful to extract

317 morphological characteristics and quantify further differences.

318 The different morphological types of particles identified in the SEM analysis could be

319 partly explained by the different livestock production systems. Particle types from feathers

320 could be explained by the feather structure and development process, related to different poultry

321 production systems. In our study, farms with 3 to 4 week-old broilers were sampled. Therefore,

322 broiler's feathers were seen as fine feathers (plumules or down feathers) with "fluffy" structure

323 to provide a high level of insulation to young birds, easily airborne as broiler chicks loose their

324 fluff (scurf). In laying hen houses, hens are generally older than 20 weeks. Therefore, laying

325 hen's feathers have more mass than and differ from down feathers. Laying hen's feathers and

326 also turkey's feathers were more similar to contour feathers than to down feathers. Contour

327 feathers consist of a shaft onto which a feather vane is attached (Leeson and Walsh, 2004). The

328 feather vane, moreover, is composed of filaments, called barbs, which have rows of interlocking

329 barbules that give the feather its shape and rigidity (Leeson and Walsh, 2004). Barbules (also

330 named hooklets after their pointed structure) are also fine structures, easily airborne, which were 
331 abundant in samples from laying hens feathers, and clearly identifiable by their pointed and

332 elongated morphology.

333 The existence of two very distinctive morphological types of manure particles between

334 poultry and pigs could be explained by the particular poultry excretory system, where urea is

335 converted chemically to uric acid. Birds excrete uric acid as encapsulated uric acid crystals

336 through bird's cloaca. Encapsulated uric acid crystals appear as round smooth spheres of

337 varying sizes as those identified in our study, surrounded by a protein material. In the case of

338 pigs, this type of excretion does not exist, and so manure particles were found as fragmented,

339 rough, and angular particles. Feddes et al. (1992) described crystals of uric acid from turkey

340 housing, as round spheres from $3 \mu \mathrm{m}$ to $8 \mu \mathrm{m}$ in diameter, and other fecal particles as similar to

341 feed particles with varying sizes from $3 \mu \mathrm{m}$ to $7 \mu \mathrm{m}$ in diameter.

342 The three types of feed particles dominant in the feed source samples were probably

343 related to different feed components: mineral particles (geometric salt-like), and more grain-like

344 organic particles (angular, cracked, fragmented particles) could be found. Outside particles were

345 mainly constituted of salt-like crystals and crustal fragmented particles. Fragmented particles

346 were comparable to soil erosion and dust particles (Skogstad et al., 1999) typical from

347 agricultural environments where livestock houses are located. The rest of the described particle

348 types (hair, skin, and wood shavings) were generally consistent with the known standards

349 (McCrone, 1992) and coherent amongst livestock categories and PM fractions.

A clear difference between mineral particles (rich in $\mathrm{Al}, \mathrm{Si}$, and $\mathrm{Ca}$ ) and organic

351 particles (rich in $\mathrm{N}, \mathrm{Na}, \mathrm{S}, \mathrm{Cl}$, and $\mathrm{Ca}$ ) could be seen in the chemical (element) composition of

352 the different sources. This difference could be made between feed and outside particles

353 (mineral) and the rest of sources (organic). Differences in element concentrations amongst

354 sources could be used by the discriminant and cluster analysis to distinguish amongst them. In

355 fact, Aarnink et al. (2004) in pigs and Cambra-López et al. (2008) in rabbits reported similar

356 elements present in PM from livestock houses. As regards mineral particles, high levels of Al

357 and Si have also been reported in crustal material (Shi et al., 2003). The presence of metallic 
trace elements could be explained by the use of some of these elements as feed supplements to

359 improve health and feed efficiency (Bolan et al., 2004). Using variations in element

360 concentrations, discriminant analysis indicated major variables useful to distinguish amongst

361 sources, providing elements which could discriminate well amongst different sources without

362 accounting for livestock categories. Cluster analysis indicated inter-relationships between

363 sources belonging to different livestock categories, providing an initial estimate of source

364 profiles per livestock category.

Particle size varied amongst sources, and mainly depended on its mineral or organic

origin. Generally disintegration particles from feed and outside source showed smaller sizes, compared with biological structures (feathers, hair, skin, and wood shavings), which were mainly larger than $4 \mu \mathrm{m}$ in diameter. Using $\mathrm{SEM}$, the $\mathrm{D}_{\mathrm{p}}$ of the particles calculated from the particle area, resulted in $\mathrm{D}_{\mathrm{p}}$ higher than $2.5 \mu \mathrm{m}$ in fine PM. This high figure could be explained by two facts: the first related to the $\mathrm{D}_{\mathrm{p}}$ being the diameter in the two-dimensional view, parallel to the plane of the filter; and the second related to the differences between geometric diameter and aerodynamic diameter. As most particles showed irregular shapes, particles would impact on the filter in their most stable orientation, generally exposing the biggest dimension on the filter plane, thus possibly explaining these high figures in $D_{p}$ (Conner et al., 2001). The geometric diameter of particles is related to its aerodynamic diameter through a dynamic shape

376 factor, which varies with the resistance force of the particle to a fluid motion (Davies, 1979).

377 Therefore, elongated particles (fibrous-like) which can show their longest axis in the direction

378 of the flow, or large and thin (flake-like) particles with low densities, could place small resistance to it, and they could be aerodynamically separated into a smaller diameter during sampling than they would if they were separated by their geometric diameter. Consequently, the accuracy of sizing particles using SEM can be reduced, as particles deviate from spheres (Willis et al., 2002). when expressed in mass. Heber et al. (1988) determined more than 50\% of particles from pig 
houses were smaller than $2.7 \mu \mathrm{m}$, and found higher particle counts in the smallest size ranges

386 for grain meal than for starch, where most particles were found to be greater than $5.4 \mu \mathrm{m}$. Our

387 results suggest that most of the generated particles from our feed samples could come from

388 grain meal rather than from starch. Furthermore, starch agglomerates, which present a specific

389 and identifiable morphology in the SEM (viewed as polyhedral or sub-spherical agglomerate

390 grains) according to McCrone (1992), were rarely seen in the analyzed particles from feed in

391 our study. Measured number PSD in the air of livestock houses have been described elsewhere

392 and have been identified as bi-modal (Lammel et al., 2004). Our results on size distributions

393 could be furthermore useful to identify similarities and differences between on-farm PSD and

394 those from known sources, taking into account differences in the measurement instruments

395 used.

396 During the experimental dust generation process, an insight of the dust potential (Miller

397 and Woodbury, 2003) of the different sources was achieved. The variable amount of sample and

398 the dust generation time needed to maximize number of particles collected on the filter

399 suggested feathers and manure were readily aerosolized, and thus showed higher dust potentials

400 compared with the rest of sources. Our results suggest that dried manure and feathers could

401 easily become airborne on-farm conditions, when exposed to air movement. This aspect should

402 be confirmed with specific source-apportionment studies in livestock houses, or by comparison

403 of on-farm samples to particle source morphologies and chemical compositions presented in this

404 study.

\section{5. Conclusions}

406 1. Distinct particle morphologies were identified in collected sources from different housing 407 systems for poultry and pigs. Detailed source profiles (morphological and chemical) for $408 \quad$ known sources were developed.

409 2. Qualitative description of particle types revealed unique morphological features related to 410 each source and different particle morphological types related to livestock production 
412 and quantify further differences.

413 3. Although presence of $\mathrm{N}, \mathrm{Na}, \mathrm{Mg}, \mathrm{Al}, \mathrm{Si}, \mathrm{P}, \mathrm{S}, \mathrm{Cl}, \mathrm{K}$, and $\mathrm{Ca}$ were identified in all

414 sources, their relative element concentrations varies amongst sources and can be used to 415 discriminate amongst them.

416 4. With the average element concentrations presented in this study, the relative

417 concentrations of $\mathrm{P}, \mathrm{N}, \mathrm{Cl}, \mathrm{S}, \mathrm{K}, \mathrm{Si}, \mathrm{Na}, \mathrm{Al}, \mathrm{Ca}, \mathrm{Mg}$, and $\mathrm{Sn}$ are useful for discriminating 418 amongst sources in fine PM. The relative concentrations of $\mathrm{P}, \mathrm{N}, \mathrm{K}, \mathrm{S}, \mathrm{Cl}, \mathrm{Al}, \mathrm{Ca}, \mathrm{Cr}, \mathrm{Na}$, $419 \mathrm{Mg}, \mathrm{Ba}$, and $\mathrm{Fe}$ are useful for discriminating amongst sources in coarse PM.

420 5. Particle size varies amongst sources (from $2.1 \mu \mathrm{m}$ to $18.1 \mu \mathrm{m}$ projected area diameter), and mainly depends on its mineral or organic origin. Generally disintegration particles from feed and outside show smaller sizes, compared with biological structures (feathers,

6. The described source specific particle-size distributions can be useful to identify similarities and differences between on-farm PSD and those from known sources.

7. Comprehensive particle characterization and complete source analysis was achieved including different housing systems for poultry and pigs in size-fractioned PM. The data presented herein and the developed source profiles will be useful to assign airborne PM samples and individual particles to known sources and to improve source identification and quantification in livestock houses, a preliminary step to develop specific strategies for

\section{Acknowledgements}


437 Universidad Politécnica de Valencia) in image analysis and M. Montero in the dust generation

438 of samples is also acknowledged.

439 7. References

440 Aarnink, A.J.A., Stockhofe-Zurwieden, N., Wagemans, M.J.M., 2004. Dust in different housing

441 systems for growing-finishing pigs. Proceedings of Engineering the Future. AgEng 2004.

442 Leuven, Belgium.

443 Blaschke, T., 2010. Object based image analysis for remote sensing. ISPRS Journal of

444 Photogrammetry and Remote Sensing 65, 2-16.

445 Bolan, N.S., Adriano, D.C., Santiago, M., 2004. Distribution and bioavailability of trace

446 elements in livestock and poultry manure by-products. Critical Reviews in Environmental

447 Science and Technology 34, 291-338.

448 Bongers, P., Houthuijs, D., Remijn, B., Brouwer, R., Biersteker, K., 1987. Lung function and

449 respiratory symptoms in pig farmers. British Journal Industrial Medicine 44, 819-823.

450 Cambra-López, M., Torres, A.G., 2008. An approach to source apportionment of dust in animal

451 houses: The case of rabbit rearing facilities. Proceedings of International Symposium Livestock

452 and Environment. ILES VIII. Iguassu, Brazil.

453 Casuccio, G.S., Schlaegle, S.F., Lersch, T.L., Huffman, G.P., Chen, Y.Z., Shah, N., 2004.

454 Measurement of fine particulate matter using electron microscopy techniques. Fuel Processing

455 Technology 85, 763-779.

456 Conner, T.L., Norris, G.A., Landis, M.S., Williams, R.W., 2001. Individual particle analysis of

457 indoor, outdoor and, community samples from the 1998 Baltimore particulate matter study.

458 Atmospheric Environment 35, 3935-3946.

459 Davies, C.N., 1979. Particle-fluid interaction. Journal of Aerosol Science 10, 477-513.

460 Donham, K.J., Leininger, J.R., 1984. Animal studies of potential chronic lung-disease of

461 workers in swine confinement buildings. American Journal of Veterinary Research 45, 926-931. 
462 Donham, K.J., Popendorf, W., Palmgren, U., Larsson, L., 1986. Characterization of dusts

463 collected from swine confinement buildings. American Journal of Industrial Medicine 10, 294-

464297.

465 Donham, K.J., Zavala, D.C., Merchant, J.A., 1984. Respiratory symptoms and lung function

466 among workers in swine confinement buildings: a cross-sectional epidemiological study.

467 Archives of Environmental Health 39, 96-101.

468 Feddes, J.J.R., Cook, H., Zuidhof, M.J., 1992. Characterization of airborne dust particles in

469 turkey housing. Canadian Agricultural Engineering 34, 273-280.

470 Grantz, D.A., Garner, J.H.B., Johnson, D.W., 2003. Ecological effects of particulate matter.

471 Environment International 29, 213-239.

472 Heber, A.J., Stroik, M., Faubion, J.M., Willard, L.H., 1988. Size distribution and identification 473 of aerial dust particles in swine finishing buildings. Transactions of the ASAE 31, 882-887.

474 IPCC, 2001. Climate Change 2001: The Scientific Basis. Houghton, J. T., Ding, Y., Griggs, D.

475 J., Noguer, M., van der Linden, P. J., Xiaousu, D. (Eds.), Intergovernmental Panel on Climate

476 Change. Cambridge University Press. Geneve, Switzerland, 944 pp.

477 Lammel, G., Schneider, F., Brüggemann, E., Gnauk, T., Röhrl, A., Wieser, P., 2004. Aerosols

478 emitted from a livestock farm in southern Germany. Water Air and Soil Pollution 154, 313-330.

479 Leeson, S., Walsh, T., 2004. Feathering in commercial poultry. I. Feather growth and

480 composition. World's Poultry Science Journal 60, 42-51.

481 McCrone, W. C. (1992). The Particle Atlas Electronic Edition (PAE2) on CD-ROM.

482 Miller, D.M., Woodbury, B.L., 2003. Simple protocols to determine dust potentials from cattle

483 feedlot soil and surface samples. Journal of Environmental Quality 32, 1634-1640.

484 NIST., 2010. Particle morphology glossary. Glossary of morphology terms. U.S. National

485 Institute of Standards and Technology. http://www.nist.gov/lispix/doc/particle-form/part-

486 morph-gloss.htm. Accessed on 21st April, 2010. 

pollution. JAMA: The Journal of the American Medical Association 287, 1132-1141.

Ruiz, L.A., Recio, J.A., Fernández-Sarriá, A., Hermosilla, T., 2010. A tool for object descriptive feature extraction: Application to image classification and map updating. Vol. XXXVIII-4/C7. The International Archives of the Photogrammetry, Remote Sensing and Spatial Information Sciences.

SAS., 2001. SAS User's Guide: Statistics. SAS Institute Inc.

Shi, Z., Shao, L., Jones, T.P., Whittaker, A.G., Lu, S., Bérubé, K.A., He, T., Richards, R.J., 2003. Characterization of airborne individual particles collected in an urban area, a satellite city and a clean air area in Beijing, 2001. Atmospheric Environment 37, 4097-4108.

Skogstad, A., Madso, L., Eduard, W., 1999. Classification of particles from the farm environment by automated sizing, counting and chemical characterization with scanning electron microscopy-energy dispersive spectroscopy. Journal of Environmental Monitoring, 379-382.

Takai, H., Pedersen, S., Johnsen, J.O., Metz, J.H.M., Groot Koerkamp, P.W.G., Uenk, G.H., Phillips, V.R., Holden, M.R., Sneath, R.W., Short, J.L., White, R.P., Hartung, J., Seedorf, J., Schroder, M., Linkert, K.H., Wathes, C.M., 1998. Concentrations and emissions of airborne dust in livestock buildings in Northern Europe. Journal of Agricultural Engineering Research 70, 59-77. modeling application framework for particle source apportionment. Chemosphere 49, 1093 1136.

510 Willis, R.D., Blanchard, F.T., Conner, T.L., 2002. Guidelines for the application of SEM/EDX analytical techniques to particulate matter samples. EPA, Washington, U.S., 88 pp. 
1 Table 1. Description of surveyed livestock houses and collected PM sources.

\begin{tabular}{|c|c|c|c|c|c|c|}
\hline $\begin{array}{l}\text { Livestock } \\
\text { species }\end{array}$ & Housing system & $\begin{array}{l}\text { Farm } \\
\text { location }\end{array}$ & Ventilation & $\begin{array}{l}\text { Number } \\
\text { of } \\
\text { animals }\end{array}$ & $\begin{array}{l}\text { Age } \\
\text { (weeks) }\end{array}$ & $\begin{array}{l}\text { Collected PM } \\
\text { source types }\end{array}$ \\
\hline \multirow{8}{*}{ Poultry } & \multirow[b]{2}{*}{ Broilers - bedding } & 1 & Tunnel & 50400 & 4 & \multirow{8}{*}{$\begin{array}{l}\text { Fresh excreta } \\
\text { Feed } \\
\text { (crumbles and } \\
\text { pellets) } \\
\text { Feathers } \\
\text { Wood } \\
\text { shavings } \\
\text { Fresh excreta } \\
\text { Feed } \\
\text { (crumbles and } \\
\text { pellets) } \\
\text { Feathers }\end{array}$} \\
\hline & & 2 & Roof & 2675 & 3 & \\
\hline & \multirow[b]{2}{*}{ Turkeys - bedding } & 1 & Ridge & 5000 & 12 & \\
\hline & & 2 & Ridge & 4040 & 10 & \\
\hline & \multirow{3}{*}{ Laying hens - floor } & 1 & Tunnel & 3850 & 71 & \\
\hline & & 2 & Tunnel & 16500 & 22 & \\
\hline & & 1 & Tunnel & 24712 & 71 & \\
\hline & Laying hens - aviary & 2 & Tunnel & 35000 & 50 & \\
\hline \multirow{6}{*}{ Pigs } & \multirow{2}{*}{ Piglets- slatted floor } & 1 & Roof & 125 & 8 & \multirow{4}{*}{$\begin{array}{l}\text { Fresh feces } \\
\text { Feed (pellets) } \\
\text { Hair }\end{array}$} \\
\hline & & 2 & Roof & 75 & 9 & \\
\hline & \multirow{2}{*}{$\begin{array}{l}\text { Growing-finishing } \\
\text { pigs - partially } \\
\text { slatted floor }\end{array}$} & 1 & Roof & 120 & 16 & \\
\hline & & 2 & Roof & 60 & 20 & \\
\hline & \multirow{2}{*}{$\begin{array}{l}\text { Dry and pregnant } \\
\text { sows - group housing }\end{array}$} & 1 & Roof & 39 & - & $\begin{array}{l}\text { Fresh feces } \\
\text { Feed (pellets) }\end{array}$ \\
\hline & & 2 & Roof & 46 & - & $\begin{array}{l}\text { Hair } \\
\text { Skin }\end{array}$ \\
\hline
\end{tabular}

2

3 Table 2. Summary of the stepwise discriminant analysis showing the squared partial correlation

4 (Partial R-Square), the F-statistic (F-value), and the probability level ( $\operatorname{Pr}>$ F), from the one-way

5 analysis of covariance in fine PM.

\begin{tabular}{lllll}
\hline Order of entrance in the model & Element & Partial R-Square & F-value & Pr $>$ F \\
\hline 1 & $\mathrm{P}$ & 0.2576 & 113.04 & $<0.0001$ \\
2 & $\mathrm{~N}$ & 0.2446 & 105.43 & $<0.0001$ \\
3 & $\mathrm{Cl}$ & 0.2392 & 102.31 & $<0.0001$ \\
4 & $\mathrm{~S}$ & 0.1456 & 55.41 & $<0.0001$ \\
5 & $\mathrm{~K}$ & 0.1161 & 42.67 & $<0.0001$ \\
6 & $\mathrm{Si}$ & 0.0475 & 16.2 & $<0.0001$ \\
7 & $\mathrm{Na}$ & 0.0406 & 13.74 & $<0.0001$ \\
8 & $\mathrm{Al}$ & 0.0318 & 10.64 & $<0.0001$ \\
9 & $\mathrm{Ca}$ & 0.0151 & 4.96 & 0.0002 \\
10 & $\mathrm{Mg}$ & 0.0125 & 4.09 & 0.0011 \\
11 & $\mathrm{Sn}$ & 0.0083 & 2.71 & 0.0190 \\
\hline
\end{tabular}

6 
7 Table 3. Summary of the stepwise discriminant analysis showing the squared partial correlation

8 (Partial R-Square), the F-statistic (F-value), and the probability level ( $\operatorname{Pr}>\mathrm{F})$, from the one-way

9 analysis of covariance in coarse PM.

\begin{tabular}{lllll}
\hline Order of entrance in the model & Element & Partial R-Square & F-value & Pr $>$ F \\
\hline 1 & $\mathrm{P}$ & 0.2963 & 139.97 & $<0.0001$ \\
2 & $\mathrm{~N}$ & 0.2629 & 118.46 & $<0.0001$ \\
3 & $\mathrm{~K}$ & 0.1772 & 71.51 & $<0.0001$ \\
4 & $\mathrm{~S}$ & 0.1371 & 52.72 & $<0.0001$ \\
5 & $\mathrm{Cl}$ & 0.1181 & 44.43 & $<0.0001$ \\
6 & $\mathrm{Al}$ & 0.0372 & 12.82 & $<0.0001$ \\
7 & $\mathrm{Ca}$ & 0.0208 & 7.04 & $<0.0001$ \\
8 & $\mathrm{Cr}$ & 0.0137 & 4.59 & 0.0004 \\
9 & $\mathrm{Na}$ & 0.0132 & 4.42 & 0.0005 \\
10 & $\mathrm{Mg}$ & 0.0108 & 3.61 & 0.0030 \\
11 & $\mathrm{Ba}$ & 0.0073 & 2.42 & 0.0340 \\
12 & $\mathrm{Fe}$ & 0.0071 & 2.37 & 0.0375 \\
\hline
\end{tabular}

10

11 Table 4. Average estimated projected area diameter $\left(D_{p}\right.$, in $\left.\mu \mathrm{m}\right)$ from particle areas from SEM

12 images and standard deviation (SD), for different sources in fine and coarse PM fractions. (N.S.

13 stands for non significant differences).

\begin{tabular}{llllll}
\hline \multirow{2}{*}{ Source } & $\mathrm{n}$ & Fraction & $\begin{array}{l}\text { Average } \\
\mathrm{D}_{\mathrm{p}}(\mu \mathrm{m})\end{array}$ & $\mathrm{SD}$ & P-value \\
\hline \multirow{2}{*}{ Feathers } & 398 & PM2.5 & 3.9 & 2.9 & $<0.0001$ \\
& 431 & PM10-2.5 & 5.6 & 5.4 & \\
Feed & 416 & PM2.5 & 2.1 & 2.2 & $<0.0001$ \\
& 405 & PM10-2.5 & 3.0 & 2.7 & \\
Hair & 34 & PM2.5 & 11.7 & 5.2 & \multirow{2}{*}{ N.S. } \\
& 36 & PM10-2.5 & 10.8 & 5.8 & \\
Manure & 644 & PM2.5 & 4.0 & 2.3 & $<0.0001$ \\
\multirow{2}{*}{ Skin } & 942 & PM10-2.5 & 5.5 & 2.8 & \\
\multirow{2}{*}{ Wood } & 27 & PM2.5 & 13.4 & 8.0 & $<0.05$ \\
shavings & 42 & PM10-2.5 & 18.1 & 8.0 & \\
Outside & 130 & PM2.5 & 4.1 & 3.3 & $<0.0001$ \\
& 212 & PM10-2.5 & 5.9 & 5.2 & \\
& 350 & PM2.5 & 2.1 & 1.9 & $<0.0001$ \\
\hline
\end{tabular}

14 

$30 \mathrm{~cm} \uparrow$

3 Figure 1. Schematic layout of dust generation process, measurements and position.

4

\section{(1)}


(a)

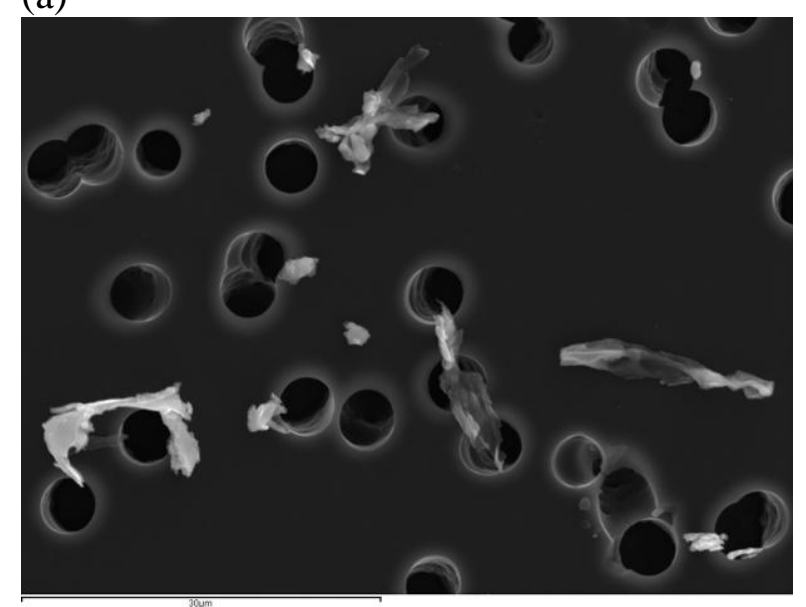

(c)

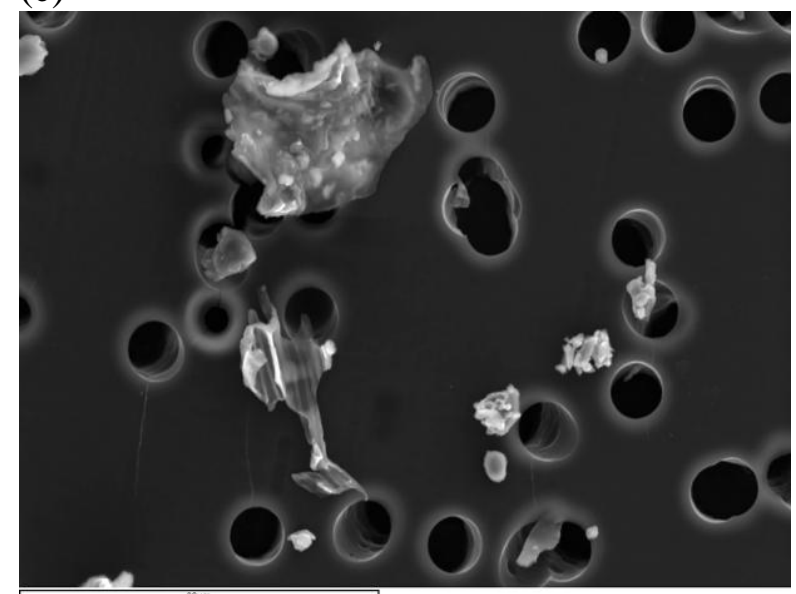

(e)

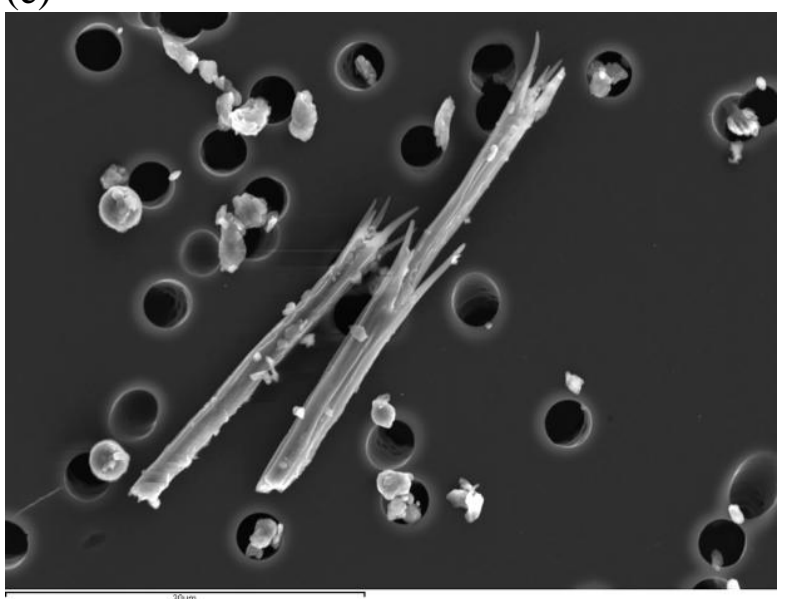

(g) (b)

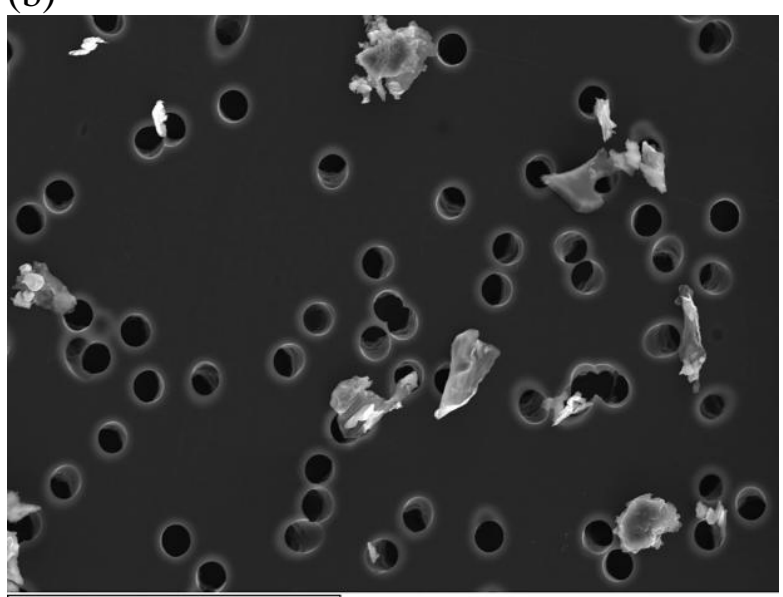

(d)

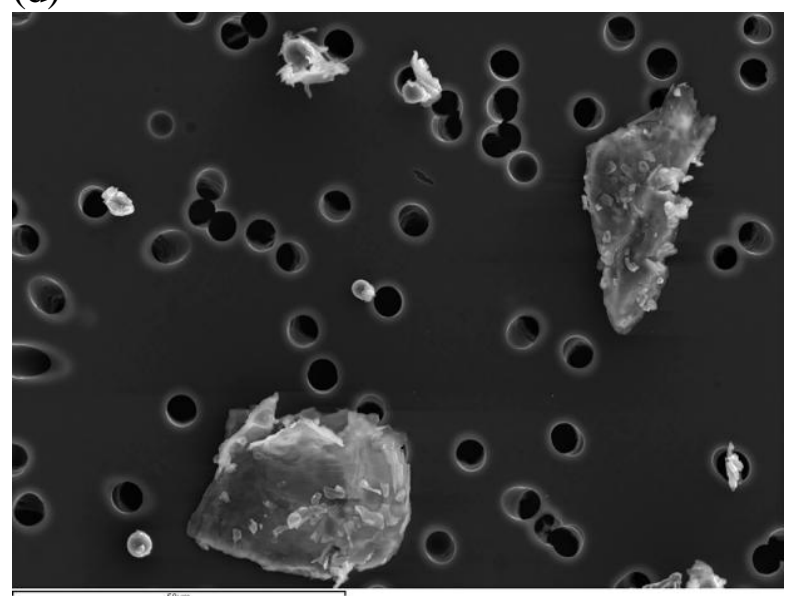

(f)

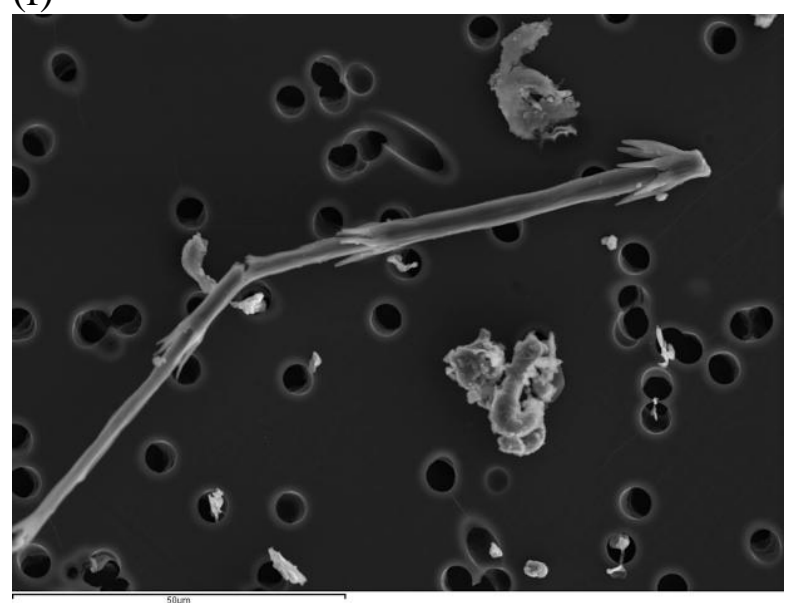

(h) 

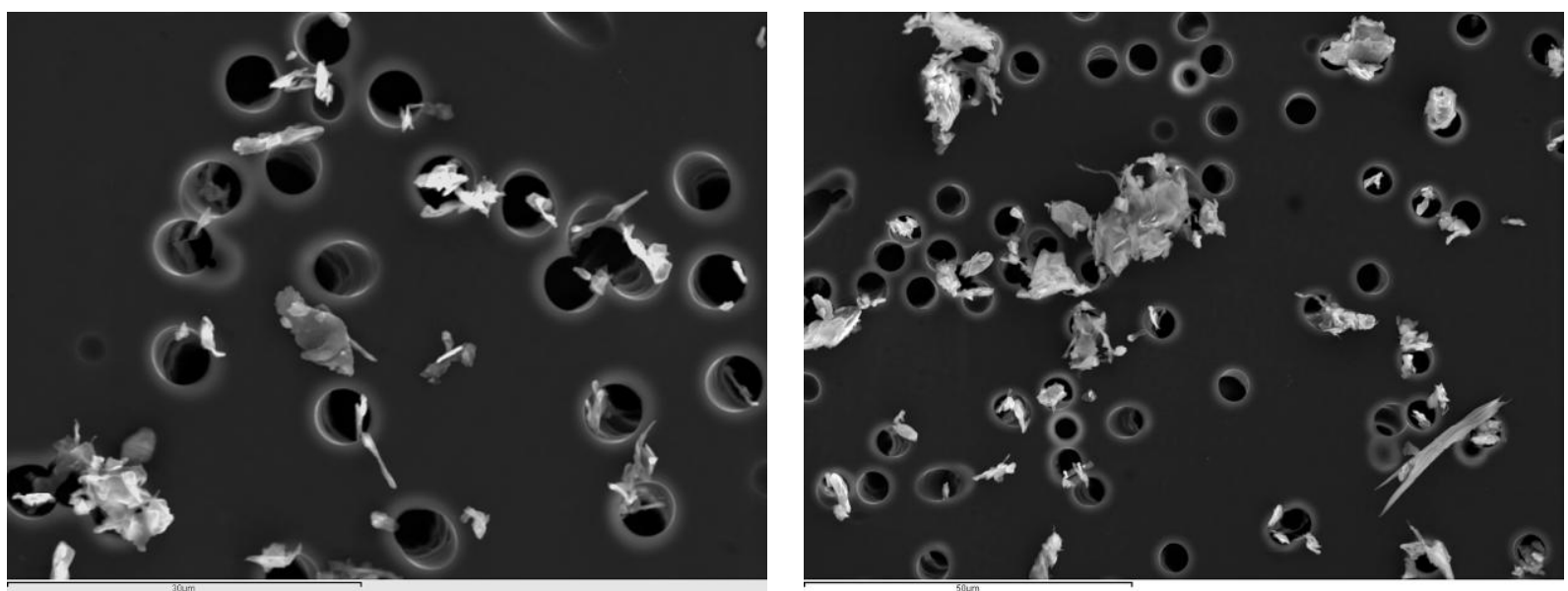

6 Figure 2. Particles from feathers. (a) Long and "fluffy" particles from broilers in fine PM. (b)

7 Mixture of "fluffy" particles showing different silhouettes from broilers coarse PM. (c) Big

8 rounded, flattened particle together with smaller "fluffy" particles from laying hens in floor

9 system fine PM. (d) Rounded and triangular flattened particles from laying hens in floor system

10 coarse PM. (e and f) Stiff, elongated, and pointed particles from laying hens in aviary system

11 fine PM (e) and coarse PM (f). (g) Soft and "fluffy" particles from turkeys in fine PM. (g)

12 Mixture of "fluffy", flake-like, and elongated particles from turkeys in coarse PM. Images on

13 the left: fine PM, scale bar $30 \mu \mathrm{m}$. Images on the right: coarse PM, scale bar $50 \mu \mathrm{m}$. Note $5 \mu \mathrm{m}$

14 diameter filter pores, shown as round dark holes. 
(a)

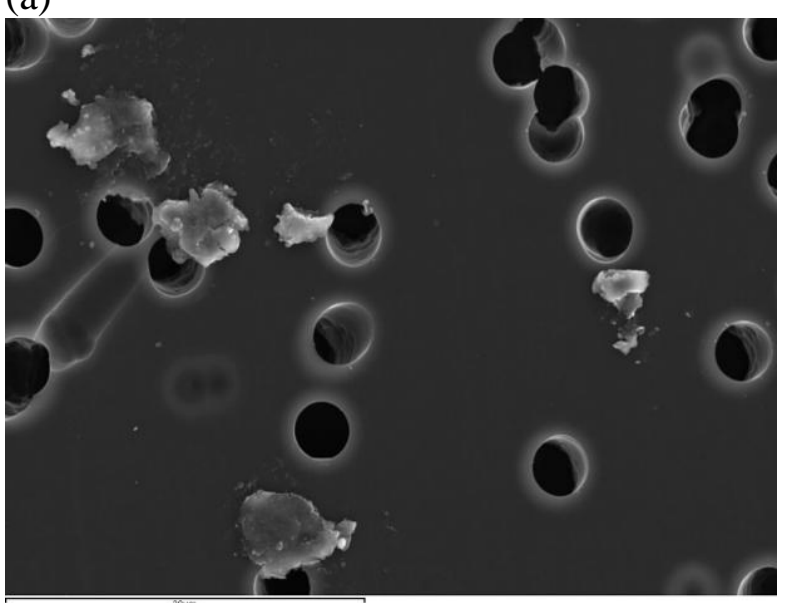

(c)

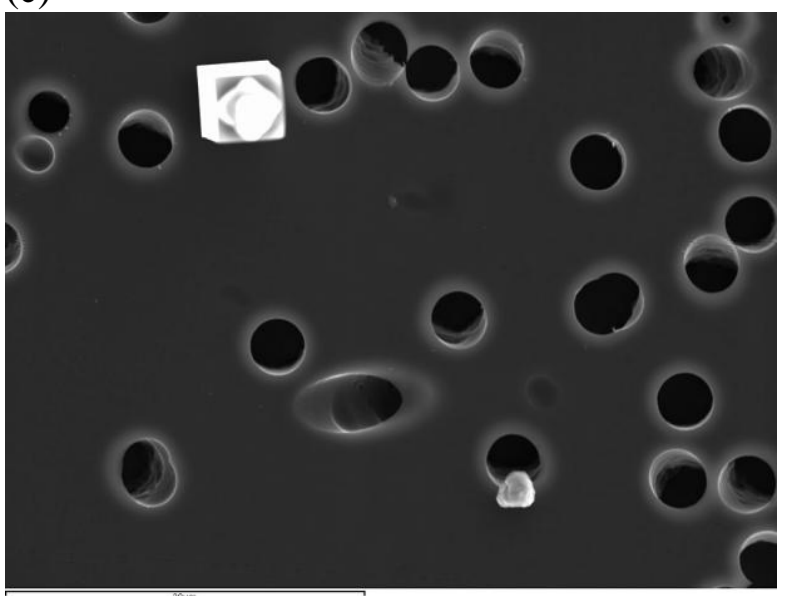

(e)

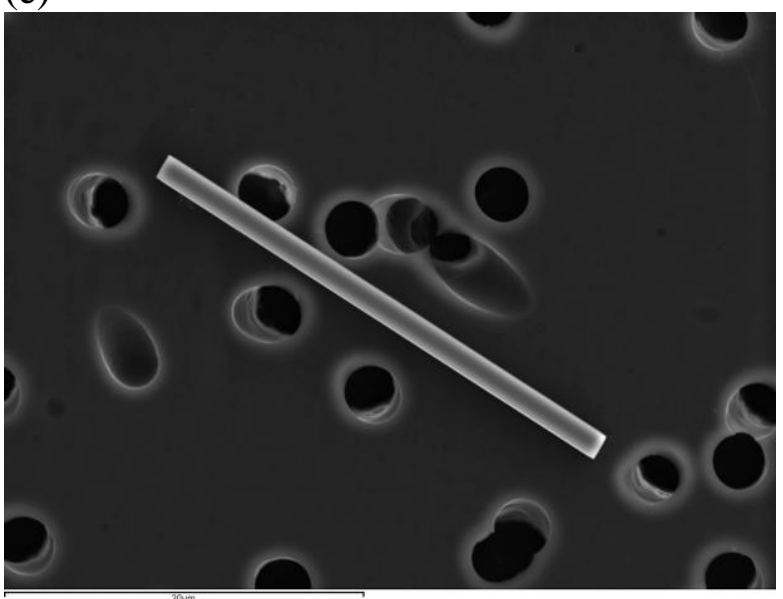

(g) (b)

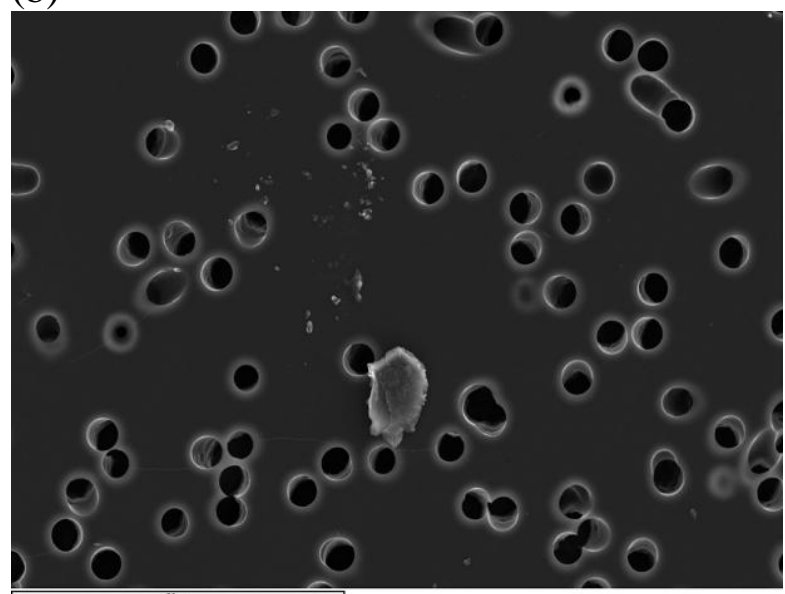

(d)

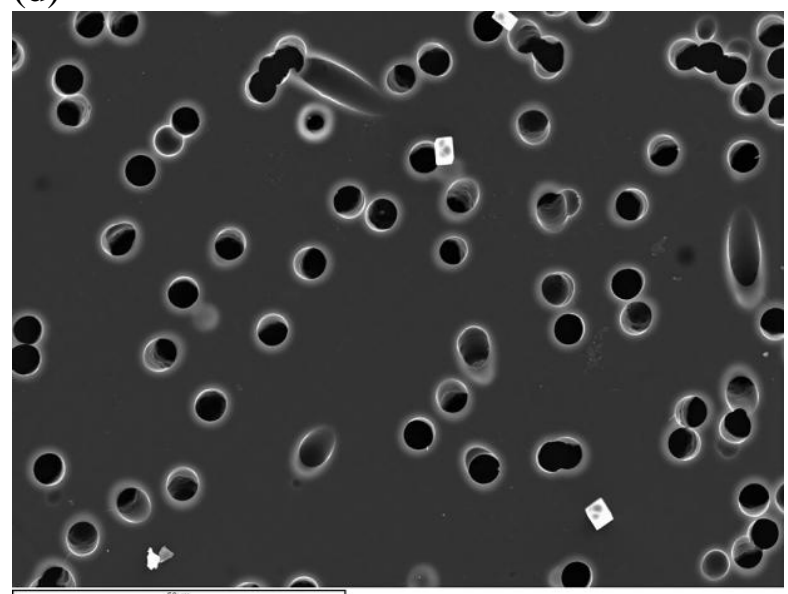

(f)

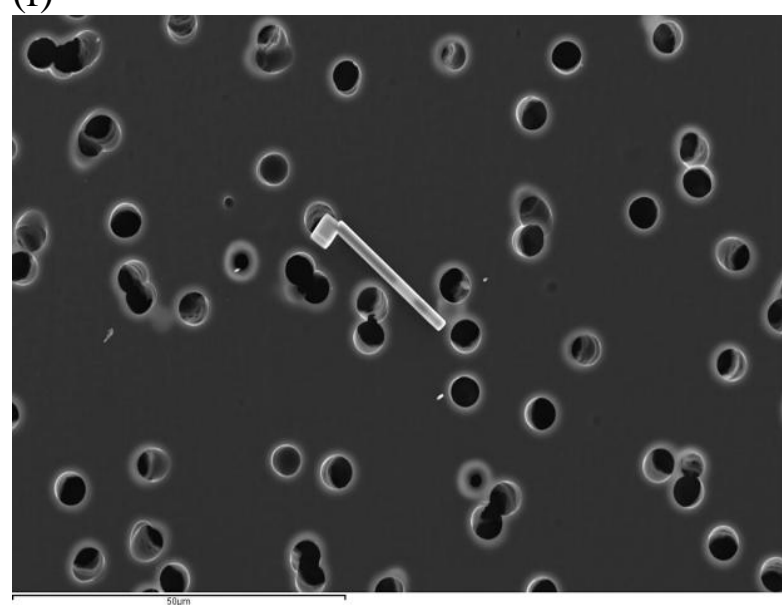

(h) 

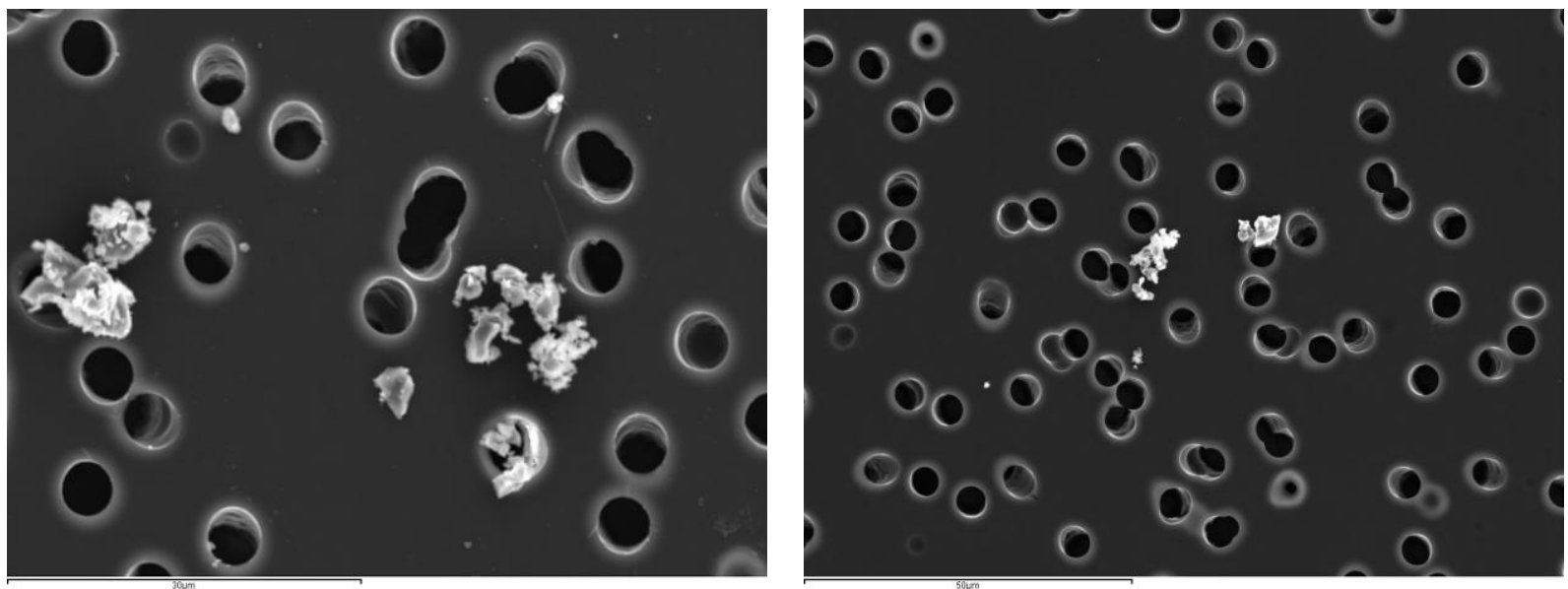

17 Figure 3. Particles from feed. (a and b) Rounded and deposited particles from broilers fine PM

18 (a) and rests of fragmented particles in coarse PM (b). (c and d) Cubic bright particles from

19 laying hens aviary system fine PM (c) and from sows coarse PM (d). (e and f) Single bar-shaped

20 particles from sows fine PM (e) and laying hens floor system coarse PM (f). (g and h) Several

21 angular, cracked, fragmented particles from laying hens aviary fine PM $(\mathrm{g})$ and growing-

22 finishing pigs coarse PM (h). Images on the left: fine PM, scale bar $30 \mu \mathrm{m}$. Images on the right:

23 coarse PM, scale bar $50 \mu \mathrm{m}$. Note $5 \mu \mathrm{m}$ diameter filter pores, shown as round dark holes. 
(a)

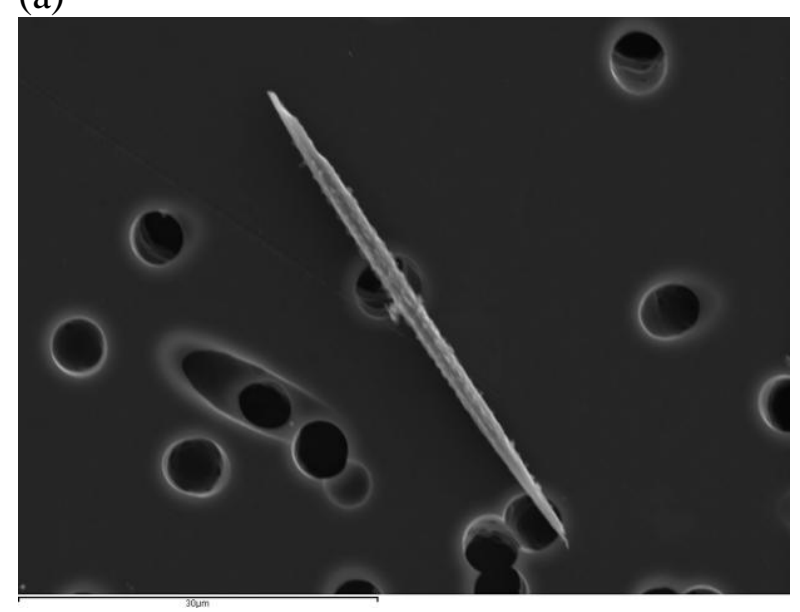

(c)

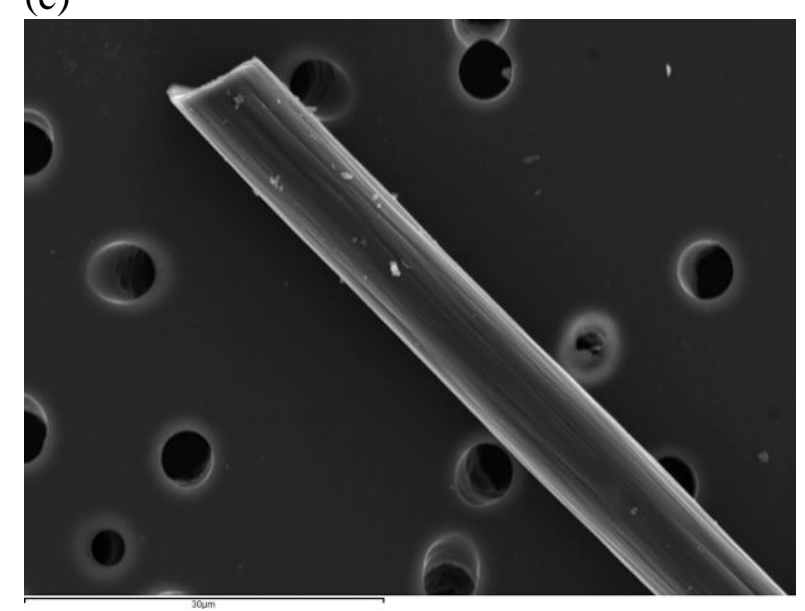

(b)

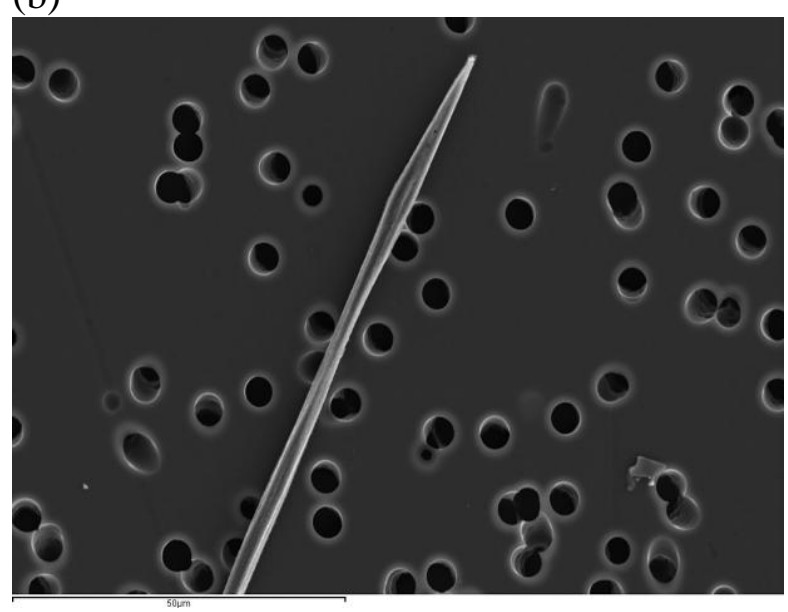

(d)

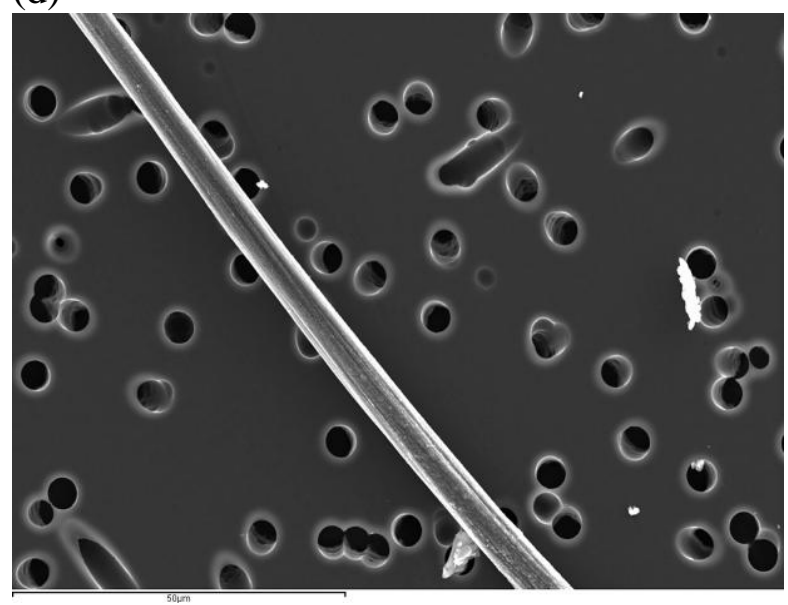

26 Figure 4. Particles from hair. (a and b) Long-thin pointed particles from growing-finishing pigs

27 fine PM (a) and from piglets coarse PM (b). (c and d) Thick and striated tubular particles from

28 growing-finishing pigs fine PM (c) and from sows coarse PM (d). Images on the left: fine PM,

29 scale bar $30 \mu \mathrm{m}$. Images on the right: coarse PM, scale bar $50 \mu \mathrm{m}$. Note $5 \mu \mathrm{m}$ diameter filter

30 pores, shown as round dark holes. 
(a)

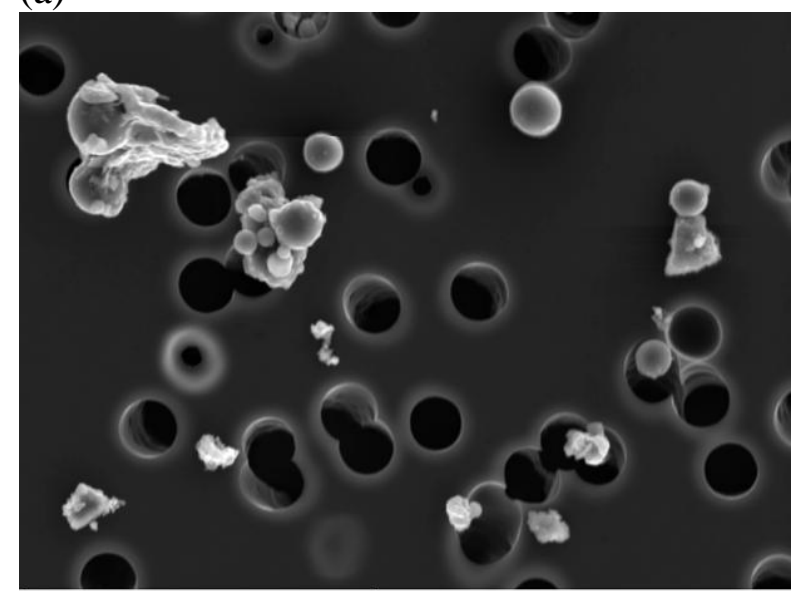

(c)

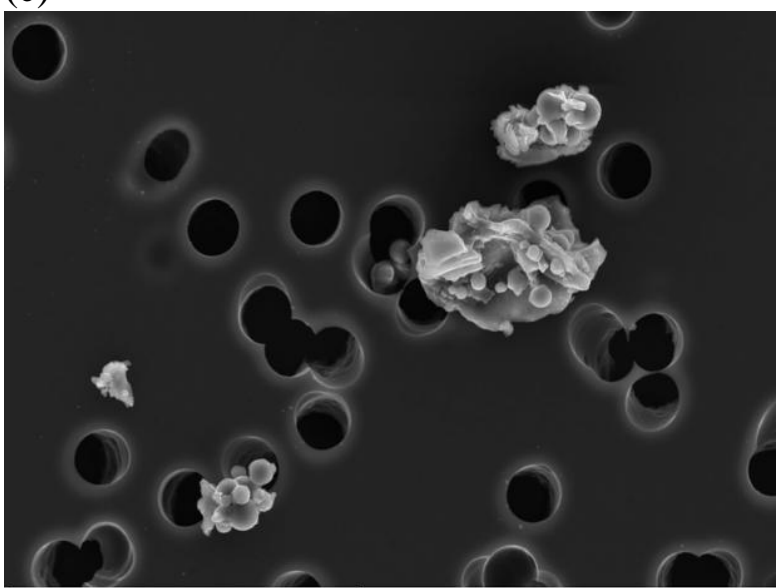

(e)

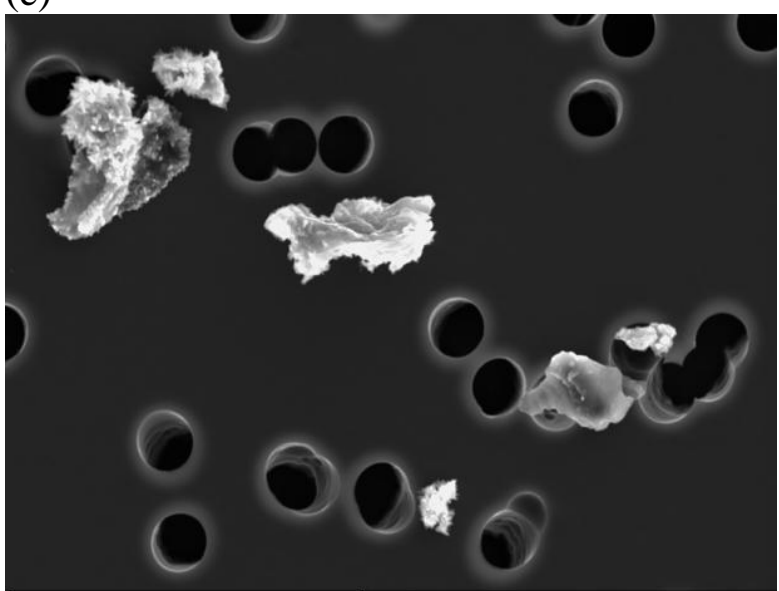

(b)

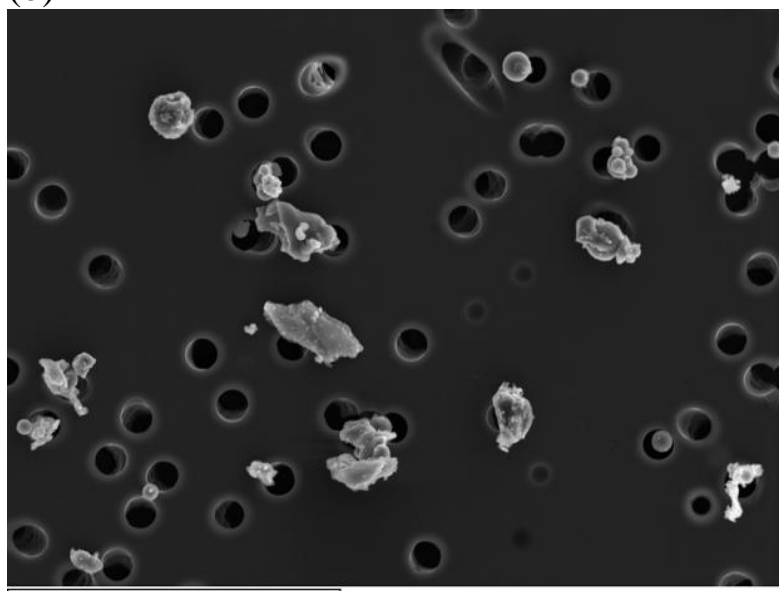

(d)

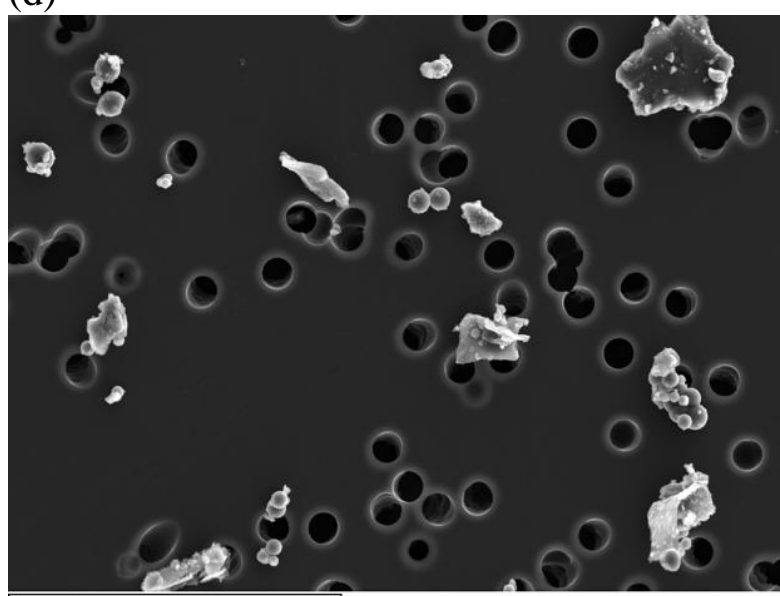

(f)

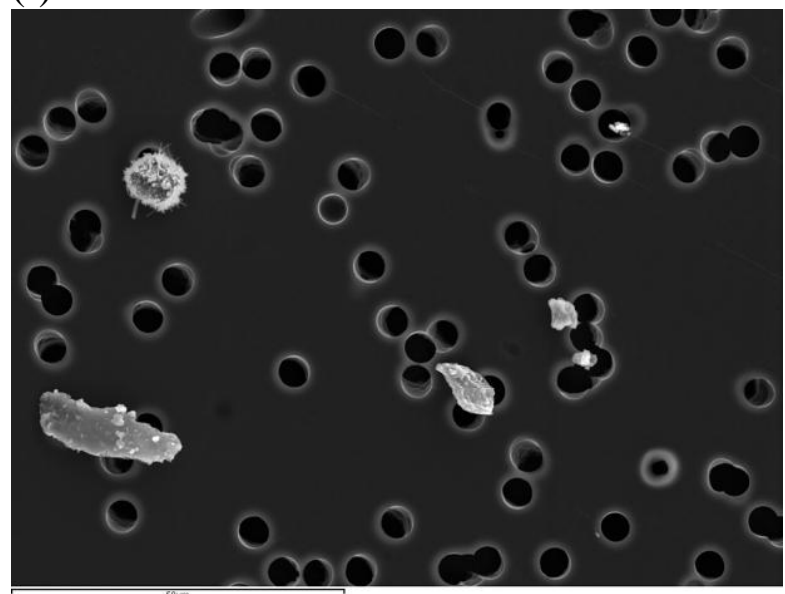

Figure 5. Manure particles from poultry. (a) Mixture of single rounded spherical and irregular

34 particles from laying hens aviary system fine PM. (b) Few single rounded spherical and more

35 abundant fragmented angular particles from laying hens aviary system coarse PM. (c)

36 Agglomerated grape-like particles from broilers fine PM. (d) Some grape-like agglomerated

37 particles and fragmented angular particles from turkeys coarse PM. (e and f) Mixture of rough, 
38 fragmented, angular and ciliated rounded particles from turkeys fine PM (f) and from laying

39 hens floor system coarse PM (f). Images on the left: fine PM, scale bar $30 \mu \mathrm{m}$. Images on the

40 right: coarse PM, scale bar $50 \mu \mathrm{m}$. Note $5 \mu \mathrm{m}$ diameter filter pores, shown as round dark holes. 
(a)

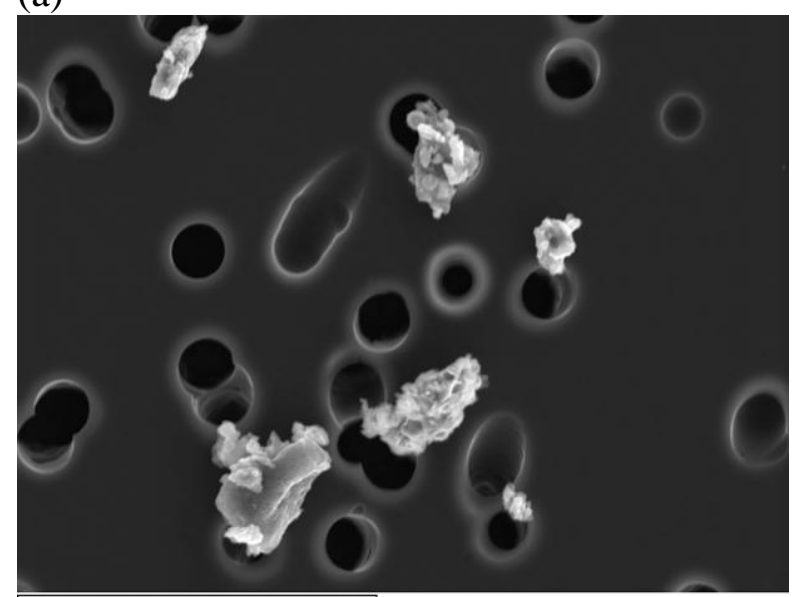

(c)

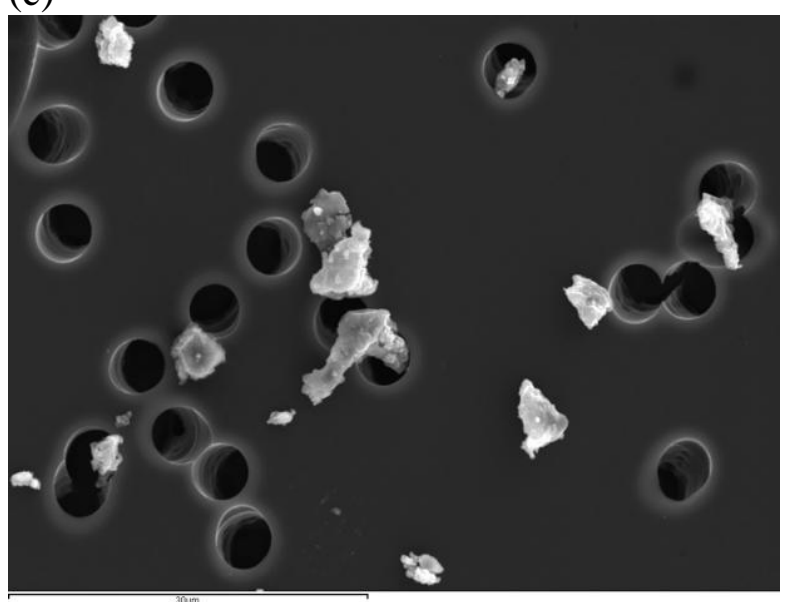

(b)

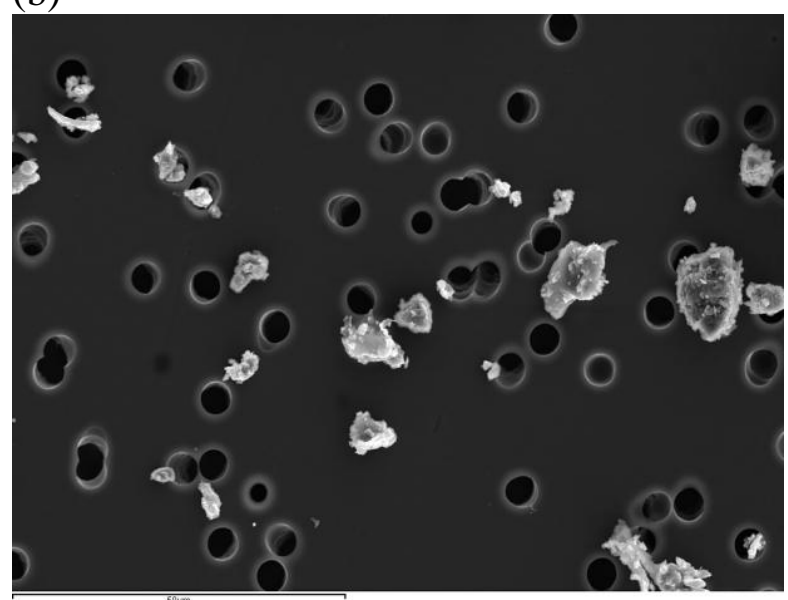

(d)

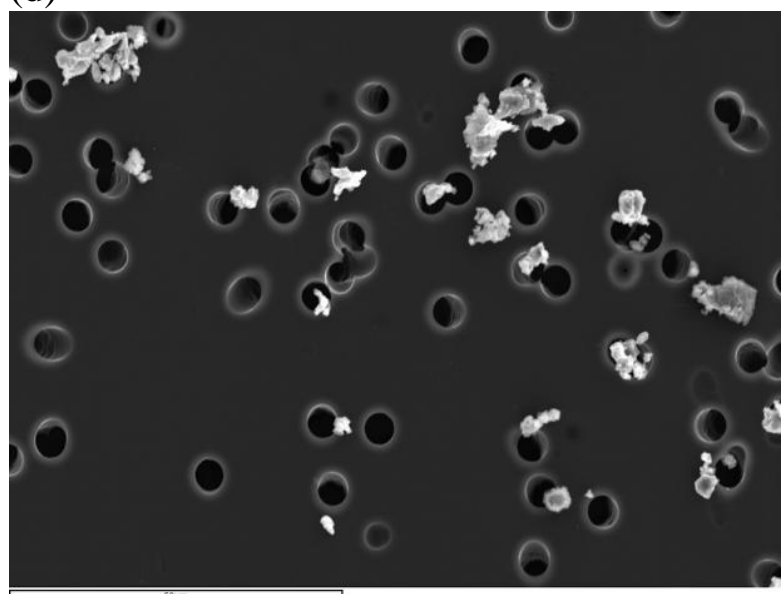

43 Figure 6. Manure particles from pigs. (a) Fragmented angular particles from piglets fine PM. (b

44 and c) Mixture of fragmented, layered, angular and more rounded particles from growing-

45 finishing coarse PM (b) and from growing-finishing fine PM (c). (d) Abundant layered and

46 angular particles from sows coarse PM. Images on the left: fine PM, scale bar $30 \mu \mathrm{m}$. Images on

47 the right: coarse PM, scale bar $50 \mu \mathrm{m}$. Note $5 \mu \mathrm{m}$ diameter filter pores, shown as round dark

48 holes. 
(a)

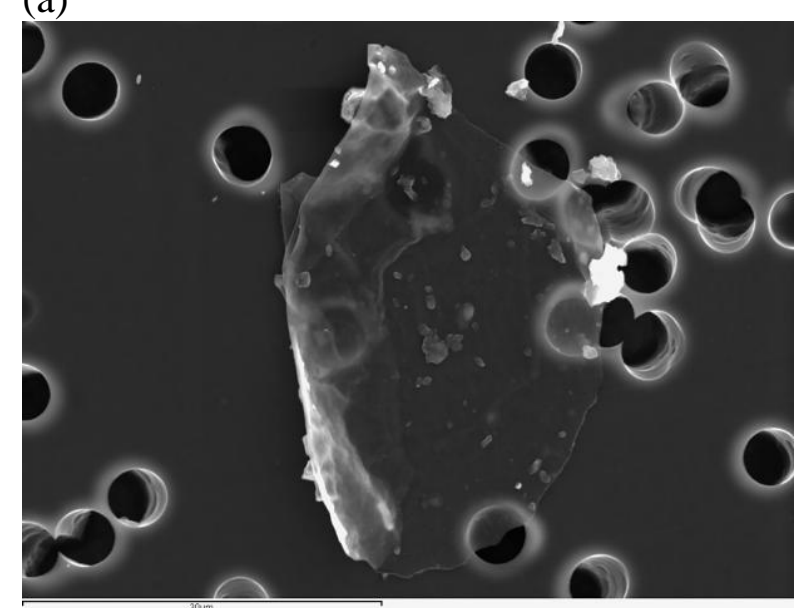

(c)

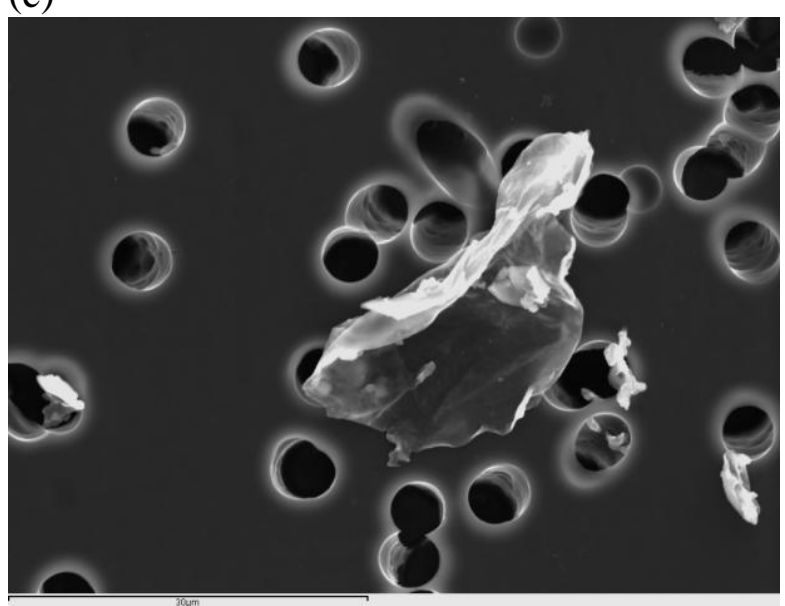

(b)

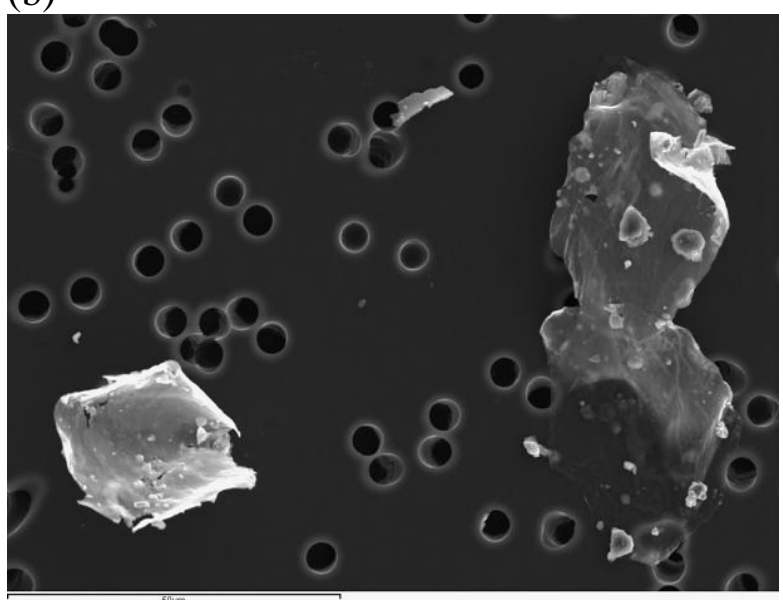

(d)

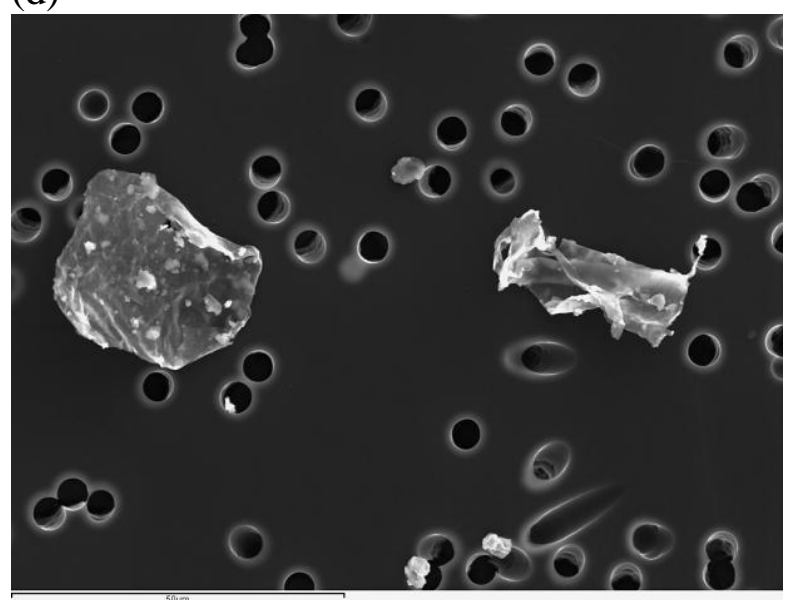

51 Figure 7. Particles from skin. All particles from sows. (a) Big, transparent, smooth, and flat

52 particle in fine PM. (b) Rounded flake-like particles from coarse PM. (c) Folded and thin

53 particle from fine PM. (d) Rough surfaces caused by deposited particles on top of flattened

54 particles from coarse PM. Images on the left: fine PM, scale bar $30 \mu \mathrm{m}$. Images on the right: coarse PM, scale bar $50 \mu \mathrm{m}$. Note $5 \mu \mathrm{m}$ diameter filter pores, shown as round dark holes. 
(a)

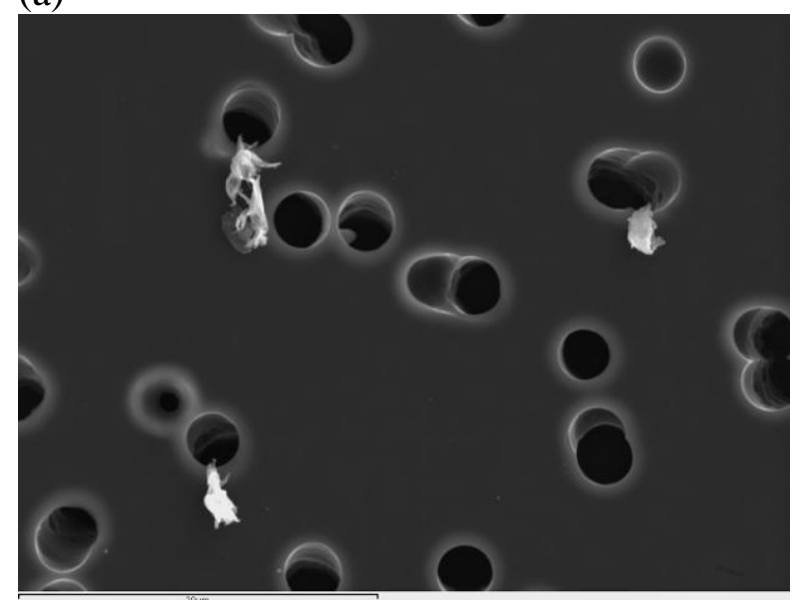

(c)

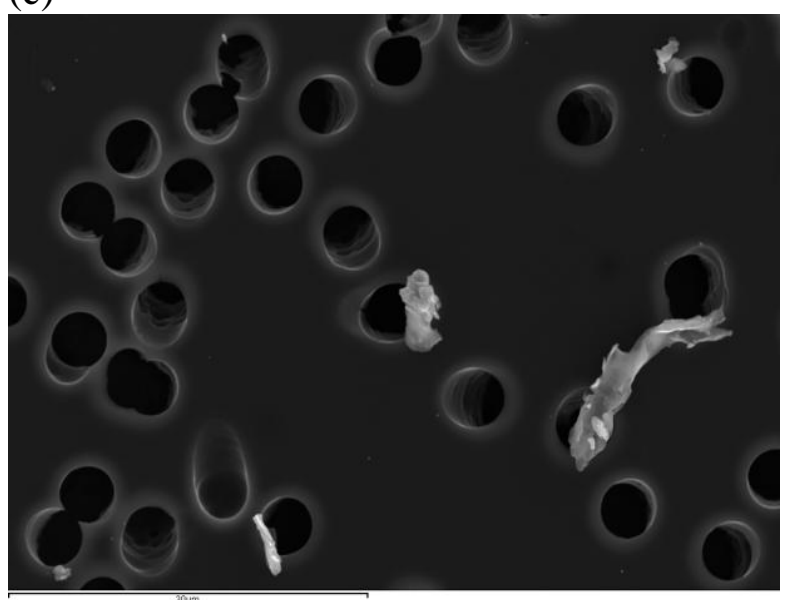

(b)

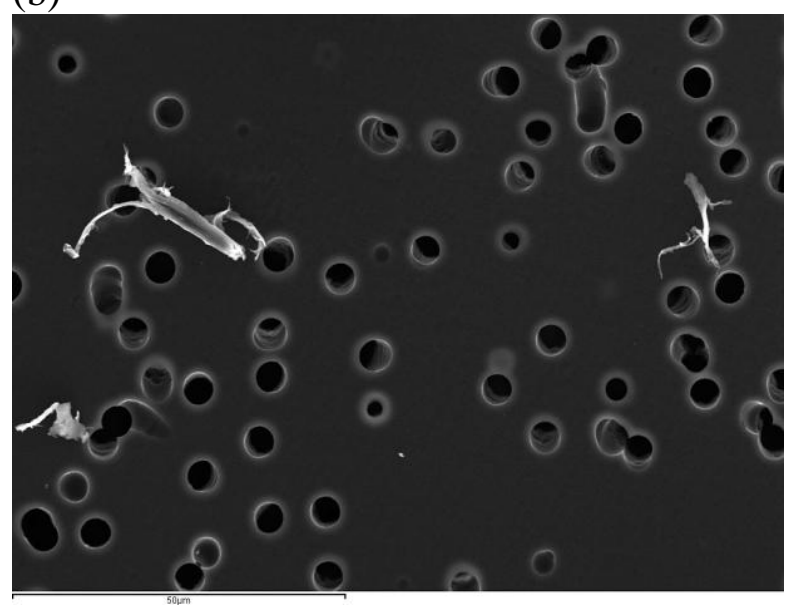

(d)

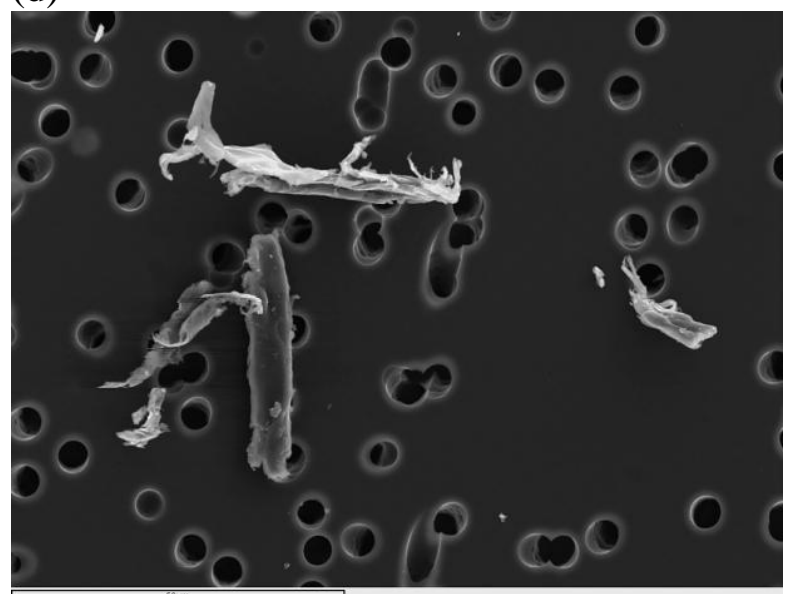

58 Figure 8. Particles from wood shavings. (a) Rounded flattened particles from broilers fine PM.

59 round with irregular borders in fine PM. (b) Fibers from broilers in coarse PM. (c) Rounded and

60 elongated, bent particle from turkeys fine PM. (d) Fibrous particles with very sharp edges from

61 broilers in coarse PM. Images on the left: fine PM, scale bar $30 \mu \mathrm{m}$. Images on the right: coarse

$62 \mathrm{PM}$, scale bar $50 \mu \mathrm{m}$. Note $5 \mu \mathrm{m}$ diameter filter pores, shown as round dark holes. 
(a)

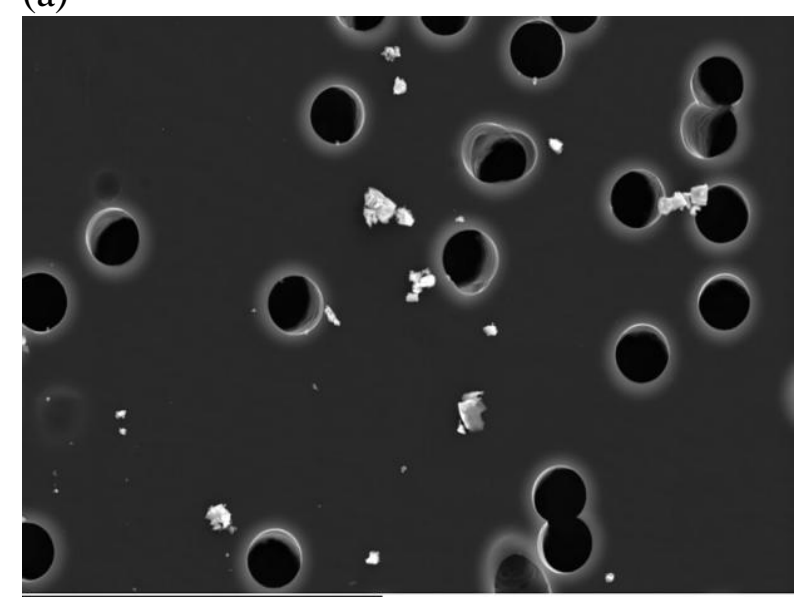

(c)

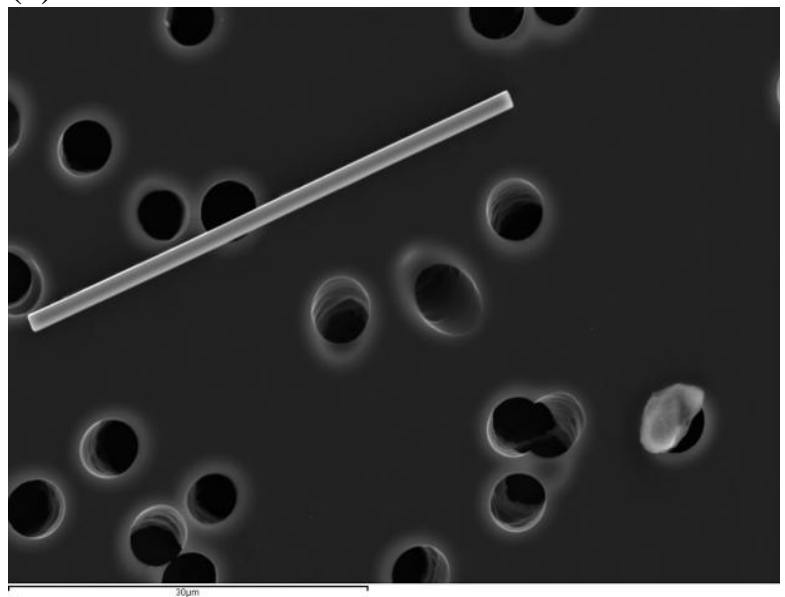

(b)

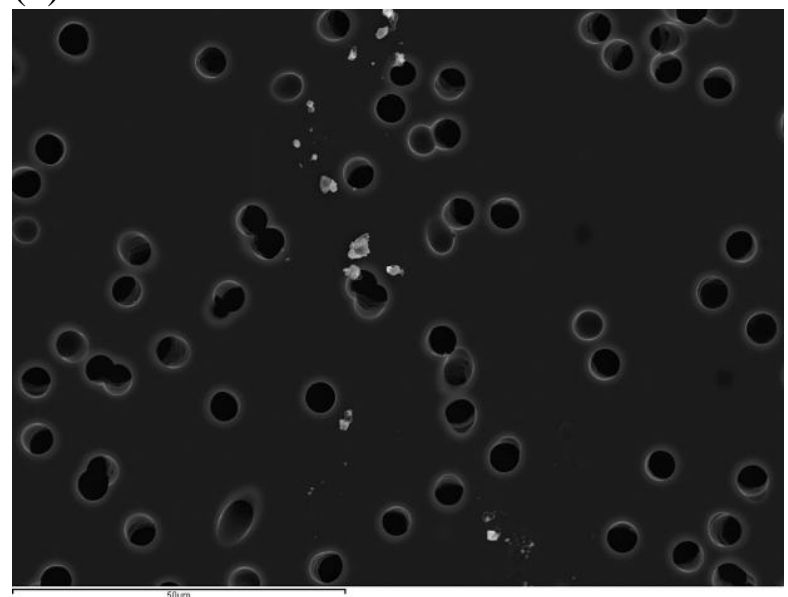

(d)

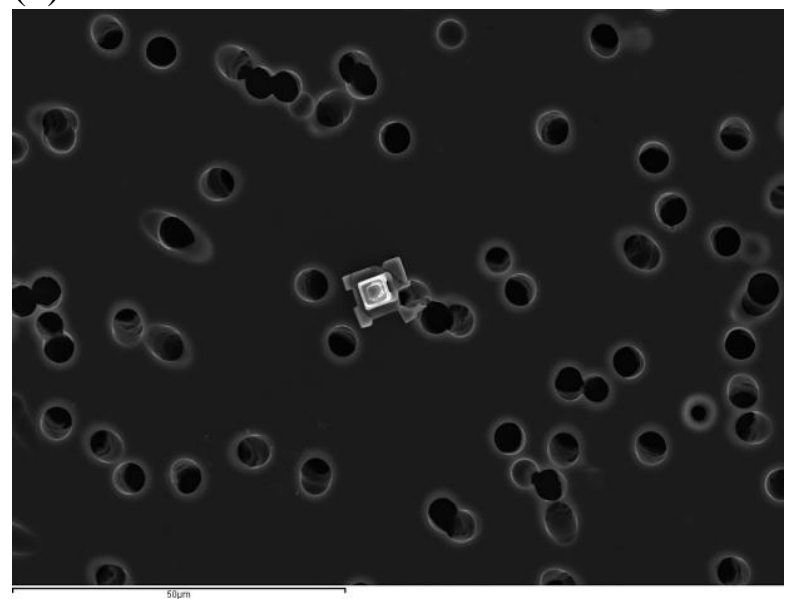

66 Figure 9. Particles from outside livestock houses. (a and b) Irregular angular, cracked, and

67 fragmented particles in fine PM (a) and coarse PM (b). (c) Bar-shaped particle in fine PM. (d)

68 Cubic particle in coarse PM. Images on the right: coarse PM, scale bar $50 \mu \mathrm{m}$. Note $5 \mu \mathrm{m}$

69 diameter filter pores, shown as round dark holes. 


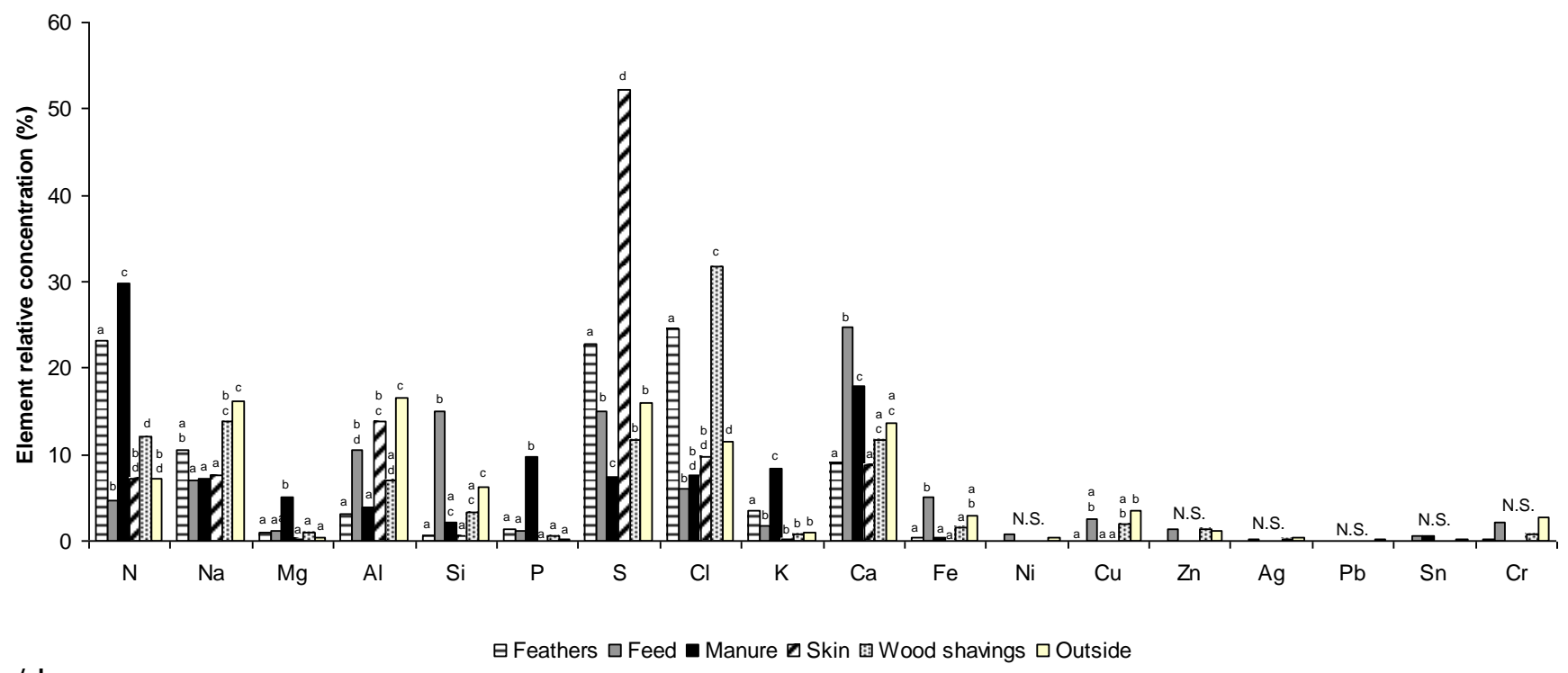

72 Figure 10. Average element relative concentration (\%) for particles from different sources in

73 fine PM2.5. Averages within an element lacking common superscript letter are significantly

74 different $(\mathrm{P}<0.05)$. (N.S. stands for non significant differences).

75 


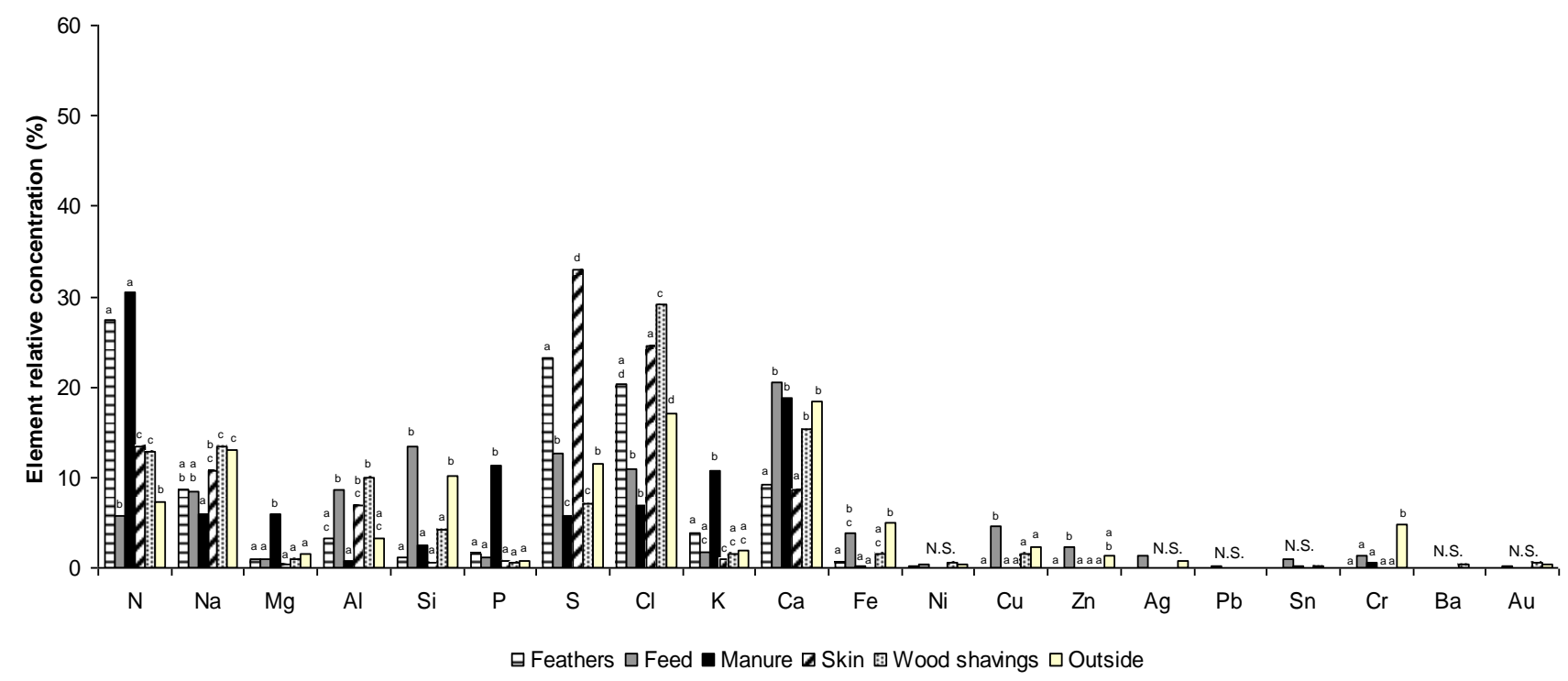

77 Figure 11. Average element relative concentration (\%) for particles from different sources in

78 coarse PM10-2.5. Averages within an element lacking common superscript letter are

79 significantly different $(\mathrm{P}<0.05)$. (N.S. stands for non significant differences). 


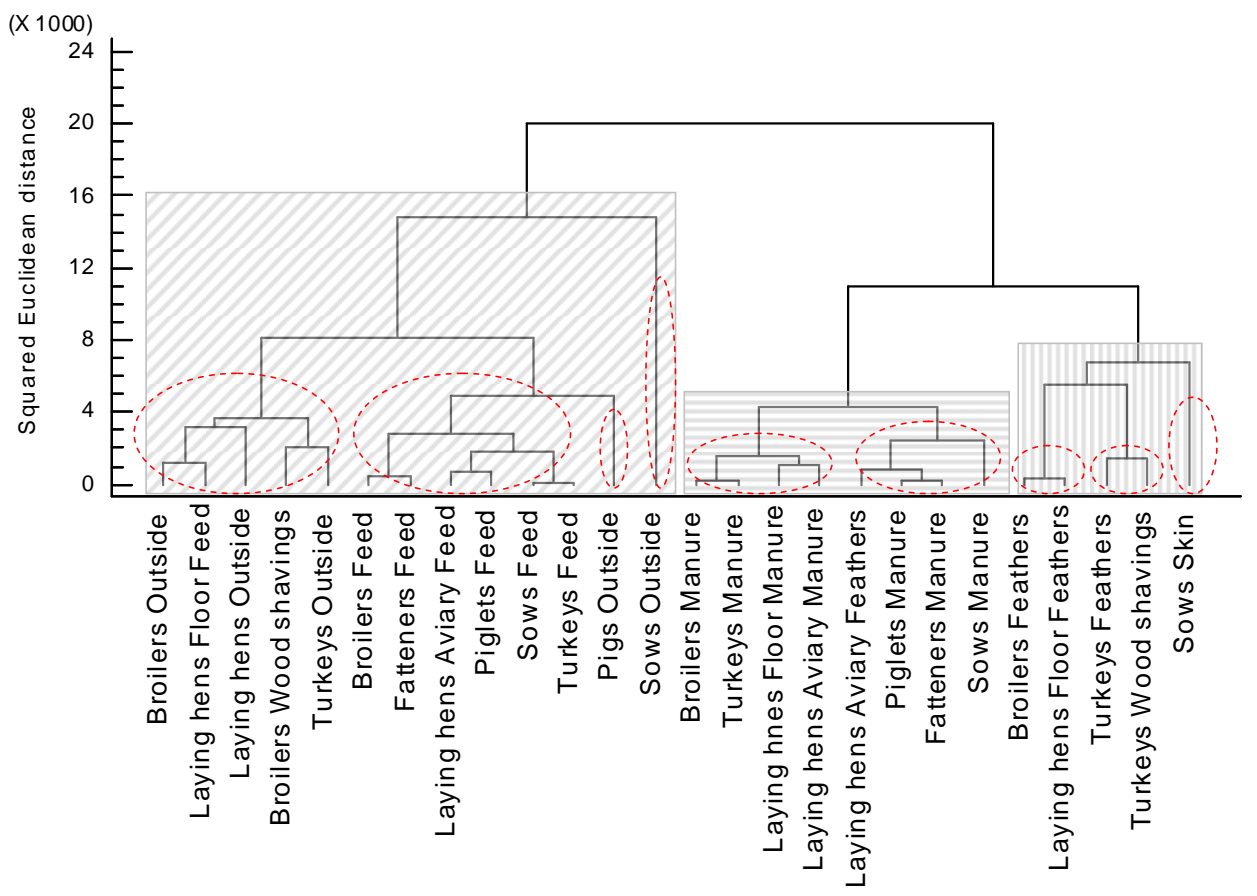

81 Figure 12. Hierarchical cluster analysis of elemental chemical concentrations of sources in

82 different livestock categories in fine PM. Ward minimum-variance method. Stripped blocks

83 represent three clusters and account for $46 \%$ variance explained by the clusters; whereas dotted 84 circles represent nine clusters and account for $82 \%$ variance. 


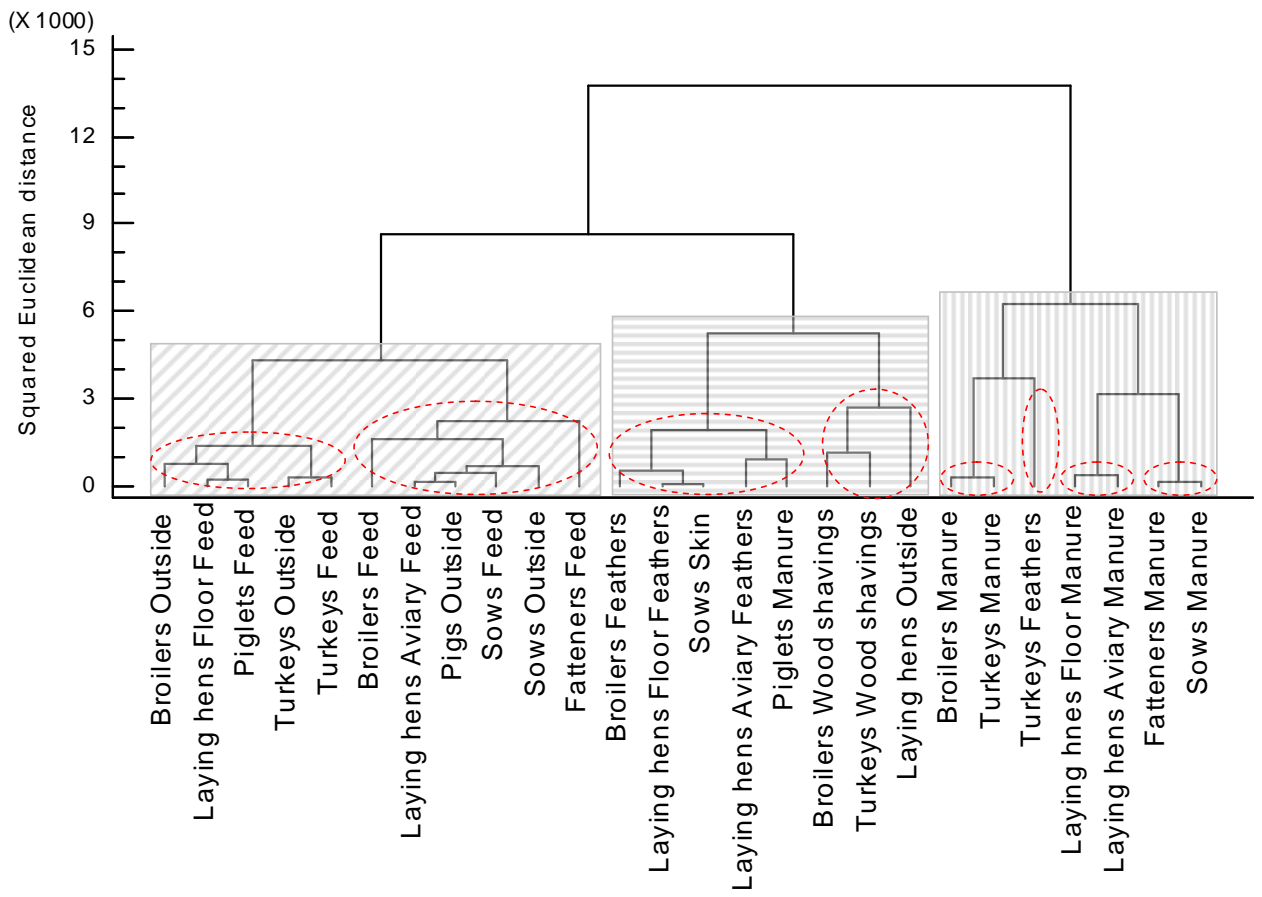

85

86 Figure 13. Hierarchical cluster analysis of elemental chemical concentrations of sources in

87 different livestock categories in coarse PM. Ward minimum-variance method. Stripped blocks

88 represent three clusters and account for $54 \%$ variance explained by the clusters; whereas dotted

89 circles represent eight clusters and account for $81 \%$ variance.

90

91 


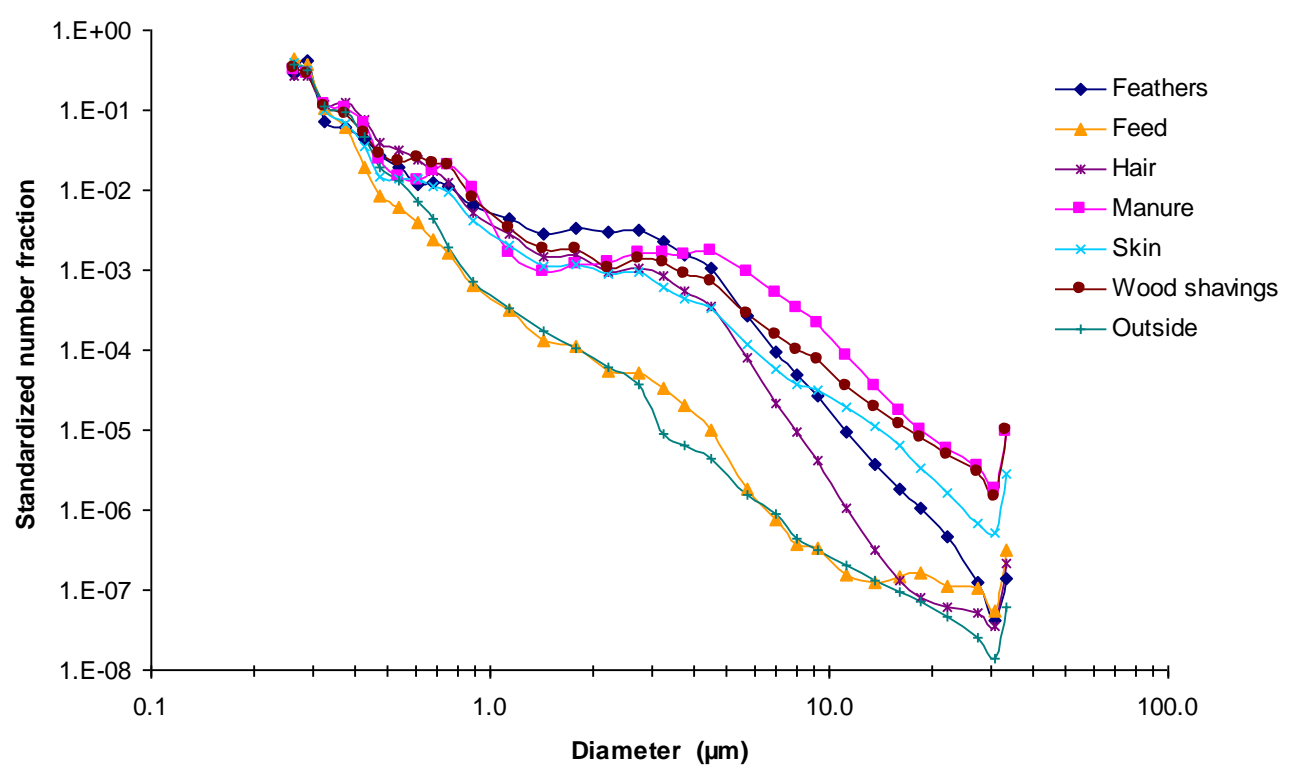

92

93 Figure 14. Standardized number fraction size distribution for particles from different sources

94 (log-scale). 


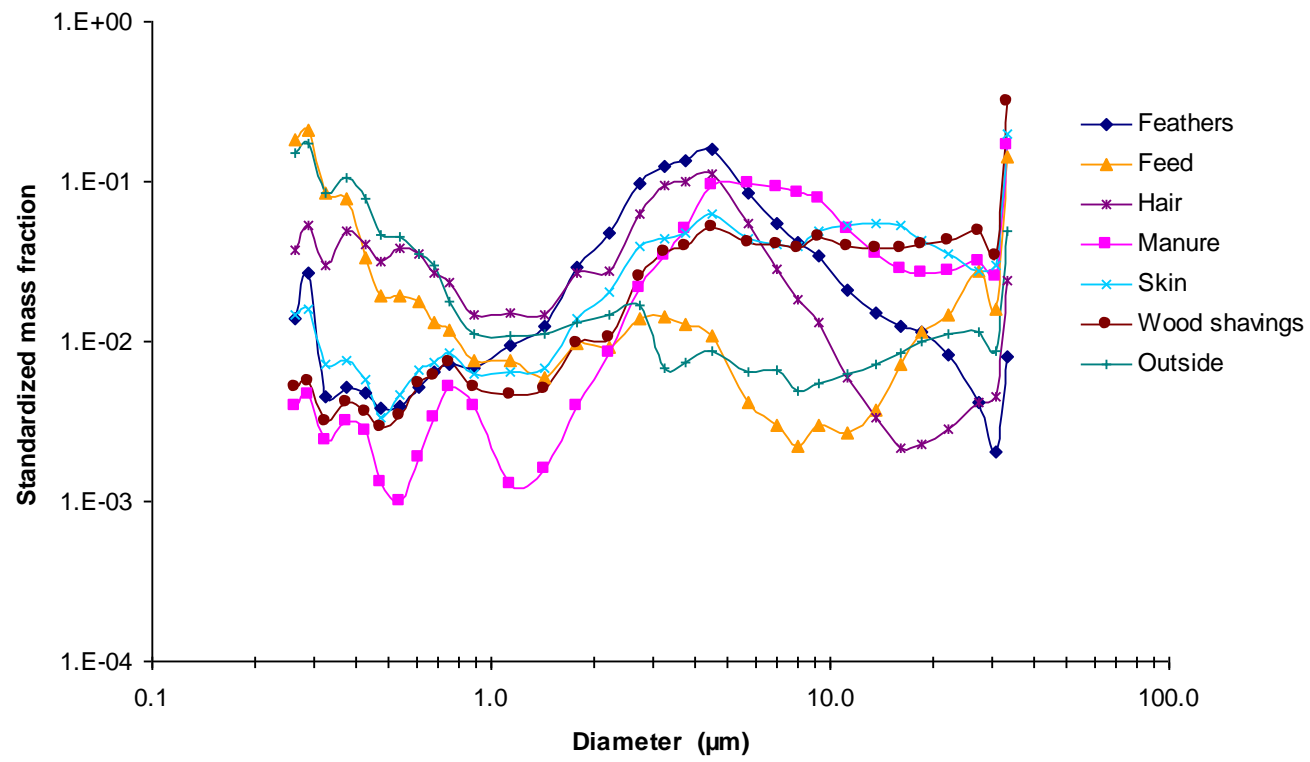

97

98 Figure 15. Standardized mass fraction size distribution for particles from different sources (log99 scale). 
Click here to download e-component: Figure 1.doc e-component
Click here to

Figure 1.doc

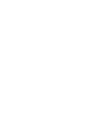

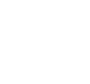

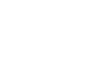

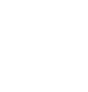

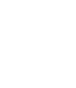

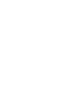

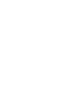

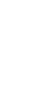

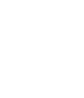

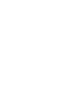

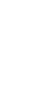
. . . .

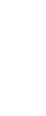

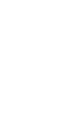

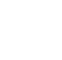
更 更

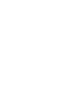

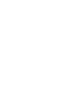
更

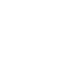

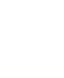

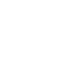

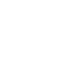

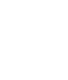

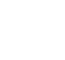


Research highlights

- Individual particles in collected sources from different housing systems for poultry and pigs show distinct and unique particle morphologies.

- Similar elements are present in all sources, but their relative element concentrations vary amongst sources and can be used to discriminate amongst them.

- Particle size and size distribution varies amongst sources and mainly depends on its mineral or organic origin.

- This work provides useful information for source identification and quantification in PM from livestock houses, improving the understanding of how PM is generated in such environments, and developing strategies for its reduction. 